\title{
Joint production and subcontracting planning of unreliable multi-facility multi-product production systems
}

\author{
M. Assid ${ }^{\text {a }}$, A. Gharbi ${ }^{\text {a, }}$, K. Dhouib ${ }^{\text {b }}$ \\ a Automated Production Engineering Department, École de technologie supérieure, Production System Design and Control \\ Laboratory, University of Québec, 1100 Notre Dame Street West, Montreal, QC, Canada H3C 1K3 \\ b Mechanical Engineering and Productique Department, École Nationale Supérieure des Ingénieurs de Tunis (ENSIT), \\ LMSSDT Laboratory, University of Tunis, 5Av. Taha Hussein, Tunis, Tunisia
}

\begin{abstract}
This article addresses the problem of joint optimization of production and subcontracting of unreliable production systems. The production system considered presents a common problem in the pharmaceutical industry. It is composed of multiple production facilities with different capacities, each of which is capable of producing two different classes of medications (brand name and generic). The resort to subcontracting is double: first, it involves the quantity of products received on a regular basis in order to compensate for insufficient production capacity in existing facilities, second, when needed, urgent orders are also launched in order to reduce the risk of shortages caused by breakdowns of manufacturing facilities. Failure, repair and urgent delivery times may be represented by any probability distributions.
\end{abstract}

The objective is to propose a general control policy for the system under consideration, and to obtain, in the case of two facilities, optimal control parameters that minimize the total incurred cost for a specific level of the customer service provided. Given the complexity of the problem considered, an experimental optimization approach is chosen in order to determine the optimal control parameters. This approach includes experimental design, analysis of variance, response surface methodology and simulation modeling. It allows the accurate representation of the dynamic and stochastic behaviours of the production system and the assessment of optimal control parameters. Other control parameters which represent the subcontracting are introduced and three joint production / subcontracting control policies (general, urgent, regular) are

\footnotetext{
${ }^{1}$ Corresponding author. Tel.: +15143968969; fax: +15143968595. E-mail addresses: morad.assid.1@ens.etsmtl.ca (M. Assid), ali.gharbi@etsmtl.ca (A. Gharbi), karemdhouib@yahoo.fr (K. Dhouib).
} 
compared to one another. The proposed joint production/regular subcontracting control policy involves a cost decrease of up to $20 \%$, as compared to results obtained by Dror et al. [1], who used a simplified control policy in addition to a heuristic solution approach for a real case study. This policy offers not only cost savings, but is also easier to manage, as compared to that proposed by Dror et al. [1]. Numerical examples and a sensitivity analysis are also performed to illustrate the robustness of the proposed control policy and the solution approach.

Keywords: Production/subcontracting control, pharmaceutical industry, service level, simulation modeling, optimization, response surface methodology.

\section{Introduction}

Manufacturing systems require continuous control and monitoring [2]. Their role has become essential thanks to an economic environment which is getting more and more competitive. In addition, manufacturing systems are getting more complex due to random fluctuations of production system components (demand, breakdowns, repairs, etc.). That is why the use of buffer stocks between workstations and at the end of the production cycle has proven to be an effective tool for protecting against random perturbations. These perturbations are often manifested through the stoppage of production activities. Despite its usefulness in maintaining customer satisfaction, having a high level of safety stocks has some disadvantages, such as increased operating and inventory costs. Low safety stock levels, however, increase the risk of shortage as well as customer dissatisfaction. The major dilemma then resides in determining the optimal level of buffer stocks to adopt which allows a reduction of the total incurred cost and ensures a high level of customer satisfaction.

The pharmaceutical field is characterized by increasingly fierce competition, a spectacular rise in the number of generic drugs and new discoveries in biotechnology. In response to these developments, pharmaceutical companies are continually seeking to improve the planning and control of the supply chain [3] as well as the efficiency of their production processes. They aim to thus minimize costs and successfully adapt their production activity to market needs. The U.S. Bureau of Labor Statistics (BLS) classifies pharmaceutical companies under three broad categories [4]: 1) producers of consumer products whose research and development activities are 
primarily focused on the development of new formulas, 2) producers of generic drugs who specialize in preparations derived from branded drugs that are no longer protected by patents, and finally, 3) designers of new molecules that produce two types of drugs (both brand name and generic), and which are usually engaged at all levels of the pharmaceutical chain of activities, namely, research and development, production, marketing. This work concerns this last category. Note that generic drugs are sold at lower prices, which explains the frequent use of subcontracting for such products, in order to reduce costs and increase production capacity. That is not the case with brand name drugs, for which patents have been issued. In this article, we are interested in the case of those pharmaceutical companies that not only produce both brand name and generic drugs, but must also resort to subcontracting in order to satisfy all customers and remain competitive. The goal is to find the production rate and the storage capacities required for each product type, as well as the subcontracting rate, which minimize the total incurred cost and maintain a specific customer service level. More specifically, it is about a problem of optimal control of production and subcontracting. In fact and according to Kaplan and Laing [5], it is a common problem in the pharmaceutical industry. Indeed, Booth [5] interprets the manufacturing priorities of pharmaceutical companies as the balance between the supply and the demand as well as the increase of the use of subcontracting in order to reduce costs incurred.

In the literature, several research studies have been undertaken to address the optimal control problem for different classes of manufacturing systems which are subject to random failures. Most of them have focused on manufacturing systems with states described by a Markov process. Olsder and Suri [7] exploited the formalism of Richel [8] and developed the dynamic programming equation of the optimal control policy for a manufacturing system operating in an uncertain environment according to a homogeneous Markov process. They focus on the production planning of a manufacturing system composed of a single machine that produces one part type and whose dynamics is described by a homogeneous Markov Chain (constant transition rates). The work of Kimemia and Gershwin [9] and Akella and Kumar [10] have shown that for such a system, the control policy known as the Hedging Point Policy (HPP) is optimal. The HPP policy consists of building an optimal safety stock (threshold) during periods of excess machine capacity. As a result, future failures of the system will be prevented, leading to greater customer satisfaction. Several authors have extended the HPP policy in order to consider practical aspects 
such as multi-state machines, random demand, preventive maintenance, quality problems, and simultaneous breakdown and quality failures $[11,12,13,14,15,16]$.

For systems with several product types, Caramanis and Sharifnia [17] use the results of Sharifnia [11] and propose a suboptimal production control policy based on a decomposition method transforming the complex multi-product control problem $\left(\mathrm{M}_{1} \mathrm{P}_{\mathrm{n}}\right)$ into several mono-product control problems $\left(\mathrm{M}_{1} \mathrm{P}_{1}\right)$ that can be treated analytically. Sethi and Zhang [18] presented an explicit formulation of the optimal control problem of a production system which consists of a single machine capable of producing several part types with negligible setup times and costs. The same hypothesis was used by Gharbi and Kenné [19] when they studied the production control problem of a manufacturing system with multiple machines and multiple product types. Bai and Elhafsi [20] elaborated the optimality conditions described by Hamilton-Jacobi Bellman (HJB) equations for a manufacturing system involving an unreliable machine. The production machine is capable of producing two part types, with non negligible setup times and costs. The authors then presented a suitable structure of the control policy, known as the Hedging Corridor Policy (HCP). Gharbi et al. [21] extended the results of Bai and Elhafsi [20] by proposing a nearoptimal control policy called the Modified Hedging Corridor Policy (MHCP).

Insufficient production capacity with respect to customer demand forced some industrial companies from different fields (pharmaceutical, automobile, aeronautics, etc.) to seek other alternatives, including subcontracting or the acquisition of new manufacturing machinery, which are used to increase production capacity and to satisfy all customers in terms of quantity and time. Dellagi et al. [22] considered a production system composed of a single machine producing one product type to satisfy a constant demand. This system calls upon a second machine (the subcontractor) to ensure the satisfaction of the demand. In the same context, Ayed et al. [23] used subcontracting as an independent production system in order to meet a random demand. Gharbi et al. [24] studied a manufacturing cell capable of producing one product type. Its total capacity changes depending on whether or not a reserve machine (stand-by) is used; a machine with a higher production cost. The proposed control policy is called the State Dependent Hedging Point Policy (SDHPP), and is characterized by two thresholds. 
Recently, Dror et al. [1] studied a common case in the pharmaceutical industry. Here, a complex production system $\left(\mathrm{M}_{2} \mathrm{P}_{2}\right)$ consisting of two facilities prone to random breakdowns and repairs is examined. These facilities have different capacities and are able to produce two medication types. The brand name medication must be produced internally, while the generic medication can be produced internally or supplied by subcontractors. The brand name and the generic medications are composed of the same main chemical substances. However, the branded medication contains special chemical additives that improve its performance characteristics. The subcontracting is intended to compensate for the lack of production capacity with respect to customer demand, and to deal with failure occurrences. The subcontracting involves an amount of drugs received on a regular basis, as well as other urgent orders which are initiated, when needed, in order to reduce the risk of shortages due to possible random breakdowns. The urgent subcontracting depends on a non-negligible and random delivery time.

Based on the HPP policy, Dror et al. [1] proposed a control policy that contributes to minimizing safety stocks and storage requirements for the two medication classes in order to reach a customer service level greater than or equal to $99.5 \%$. The authors used several restrictions and assumptions which affect the quality of the results. They proposed a heuristic approach which ignores the dynamic aspects of the production system, the random delivery times and breakdowns, and above all, it also ignores production, subcontracting, inventory carrying and shortage costs. However, the majority of the works in the scientific literature covering production systems indicate that it is important to take into consideration the incurred cost as the main decision criterion in tackling the concerns of the company's decision makers.

Our objective is to propose a better joint production/subcontracting control policy and an efficient solution approach to this complex problem for a manufacturing system composed of multiple production facilities and producing two product types $\left(\mathrm{M}_{\mathrm{i}} \mathrm{P}_{2}, \mathrm{i} \in\{1, \ldots, \mathrm{m}\}\right)$. This will be achieved by simultaneously considering costs and customer satisfaction as two decision criteria in order to deal with the concerns of decision makers. We also explain the relationship between the customer service level, the total incurred cost and the control parameters of the production system. It is important to note that no other researchers, except Dror et al. [1], have addressed the control problem presented in this work. The proposed experimental solution approach combines 
statistical methods with simulation modeling in order to evaluate the best control parameters (i.e.: control parameters that minimize the total incurred cost while respecting the customer satisfaction constraint). It is based on experimental design, analysis of variance, response surface methodology, as well as simulation modeling. In fact, simulation is an effective tool which allows us to take into account the dynamic and stochastic nature of such a complex production system. The proposed approach will eliminate the simplification and the unrealistic assumptions imposed by Dror et al. [1], and will accurately reproduce the behavior of the production system [25]. The rest of this article is organized as follows. In section 2, the joint production/subcontracting control problem of the pharmaceutical production system (multiple facilities / two product types: $\left.\mathrm{M}_{\mathrm{i}} \mathrm{P}_{2}, \mathrm{i} \in\{1, \ldots, \mathrm{m}\}\right)$ is formulated analytically. Sections 3 and 4 respectively present the experimental solution approach adopted and the simulation model developed. Section 5 summarizes the solution approach proposed by Dror et al. [1], the system's data, and the main obtained results. In section 6 , we use the proposed solution approach to determine the optimal parameters of the control policy based on Dror's control policy. A comparative study of the results generated by the proposed approach and that of Dror et al. [1] is also carried out. Section 7 presents the comparison of three control policies which integrate the subcontracting parameters as decision variables. The best joint production/subcontracting control policy obtained is then studied in depth in Section 8, and compared to the Dror's results. Sensitivity analyses are also carried out to confirm the robustness of the joint control policy and the solution approach.

\section{Notations and problem formulation}

\subsection{Notations}

Let $\mathrm{I}=\{1,2\}$ and $\mathrm{J}=\{1,2, \ldots, \mathrm{m}\}$.

$\mathbf{P}_{\mathbf{i}} \quad:$ Type of product, $\mathrm{i} \in \mathrm{I}\left(\mathrm{P}_{1}\right.$ : the brand name medication, $\mathrm{P}_{2}$ : the generic medication)

$\mathbf{x}_{\mathbf{i}}(\mathbf{t}) \quad$ : Inventory level (or backlog) of product $P_{i}$ at time $t, i \in I$,

$\mathbf{d}_{\mathbf{i}} \quad$ : Demand rate of the product $\mathrm{P}_{\mathrm{i}}, \mathrm{i} \in \mathrm{I}$

$\mathbf{u}^{\mathrm{ij}}(\mathbf{t}) \quad:$ Production rate of the product $\mathrm{P}_{\mathrm{i}}$ at the facility $\mathrm{M}_{\mathrm{j}}$ at time $\mathrm{t}, \mathrm{i} \in \mathrm{I}, \mathrm{j} \in \mathrm{J}$

$\mathbf{u}^{\mathbf{i}}(\mathbf{t}) \quad:$ Production rate of the product $\mathrm{P}_{\mathrm{i}}$ at time $\mathrm{t}, \mathrm{i} \in \mathrm{I}$

$\mathbf{U}_{\max }^{\mathrm{ij}} \quad$ : Maximum production rate of the product $P_{\mathrm{i}}$ at the facility $\mathrm{M}_{\mathrm{j}}, \mathrm{i} \in \mathrm{I}, \mathrm{j} \in \mathrm{J}$ 
$\mathbf{U}_{\mathbf{s t}}^{\mathbf{R}} \quad$ : Regular subcontracting rate of product $\mathrm{P}_{2}$

$\mathbf{Q}_{\mathbf{s t}}^{\mathbf{U}}(\mathbf{t}) \quad$ : Urgent subcontracting quantity of product $\mathrm{P}_{2}$ received at time $\mathrm{t}$

$\mathbf{U}_{\mathbf{s t}}(\mathbf{t}) \quad$ : Subcontracting rate of product $\mathrm{P}_{2}$ at time $\mathrm{t}$

$\mathbf{Z}_{\mathbf{i}} \quad$ : Storage space capacity of the product $\mathrm{P}_{\mathrm{i}} \mathrm{i} \in \mathrm{I}$

$\mathbf{M T B F}_{\mathbf{j}}:$ Mean time between failures of the facility $\mathrm{M}_{\mathrm{j}}, \mathrm{j} \in \mathrm{J}$

$\mathbf{M T T R}_{\mathbf{j}}:$ Mean time to repair of the facility $\mathrm{M}_{\mathrm{j}}, \mathrm{j} \in \mathrm{J}$

$\mathbf{c}_{\mathbf{i}}^{+} \quad:$ Product type $\mathrm{i}$ inventory cost per time unit per item, $\mathrm{i} \in \mathrm{I}$

$\mathbf{c}_{\mathbf{i}}^{-} \quad$ : Product type i backlog cost per time unit per item, i $\in$ I

$\mathbf{c}^{\mathbf{e}} \quad$ : Storage space cost per time unit per item

$\mathbf{c}_{\mathbf{i j}}^{\mathbf{p}} \quad:$ Production cost of the facility $M_{j}$ per item of $P_{i}, i \in I, j \in J$

$\mathbf{c}_{\mathbf{s t}}^{\mathbf{R}} \quad$ : Regular subcontracting cost per item

$\mathbf{c}_{\mathbf{s t}}^{\mathbf{u}} \quad$ : Urgent subcontracting cost per item

TD : Random transportation delay of the urgent subcontracting

\subsection{Problem formulation}

The problem consists of multiple production facilities with different capacities, and each of which is capable of producing two distinct types of products: branded medication $\left(\mathrm{P}_{1}\right)$ whose company is the only producer, and generic medication $\left(\mathrm{P}_{2}\right)$. Before being delivered to customers, each type of product is stored in a storage space under ideal conditions in order to preserve its quality [1]. Unlike other works as [26] and [27], which considered a system with deteriorating item, both product types $\left(\mathrm{P}_{1}\right.$ and $\left.\mathrm{P}_{2}\right)$ do not present any risk of degradation related to quality. The production facilities are subject to random breakdowns and repairs that can generate stock-outs. The company can provide the product $\mathrm{P}_{2}$ from external sources in order to increase the production capacity of facilities or perhaps to deal with the occurrence of failures. The subcontracting consists of an amount of medications received on a regular basis $\left(U_{s t}^{R}\right)$ and of other urgent orders $\left(Q_{s t}^{U}\right)$ launched to reduce the risk of shortages, when needed. It should be noted that urgent orders are characterized by a transportation delay of TD time units, where TD is a random variable. This implies that urgent orders launched at time $t$ arrive to the inventory of finished product $\mathrm{P}_{2}$ at time $(\mathrm{t}+\mathrm{TD})$. Figure 1 describes the structure of the production system. 
Because of the random occurrence of breakdowns and repair activities, the state of the system is modeled by two components, the level of accumulated inventory of both products $\mathrm{X}(\mathrm{t})=\left(\mathrm{x}_{1}(\mathrm{t}), \mathrm{x}_{2}(\mathrm{t})\right) \in \mathrm{R}^{2}$ with a continuous nature in time and the stochastic process $\alpha_{j}(t) \in B_{j}=\{0,1\}(1 \leq j \leq m)$ that describes the operating mode of the facility $M_{j}$. Such a facility is available when it is operational $\left(\alpha_{\mathrm{j}}(\mathrm{t})=1\right)$ and not available when it is under repair $\left(\alpha_{j}(t)=0\right)$. The manufacturing system mode can be described by the random vector $\alpha(t)=\left(\alpha_{1}(t), \ldots, \alpha_{m}(t)\right)^{\prime}$ with values in $B=B_{1} x_{2} x \ldots x B_{m}$.

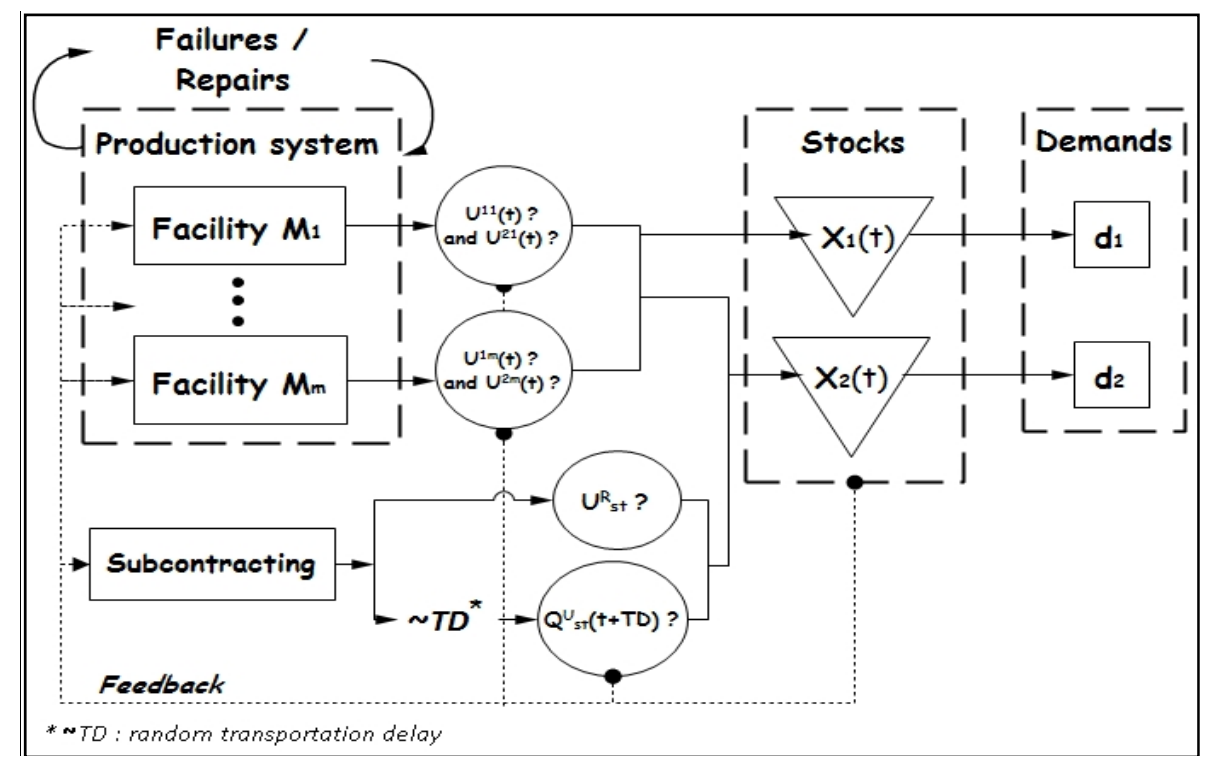

Figure 1. The considered pharmaceutical production system

The dynamic behavior of the system is described by the state variables $(X(t), \alpha(t))$, with $\mathrm{X}(\mathrm{t})=\left(\mathrm{x}_{1}(\mathrm{t}), \mathrm{x}_{2}(\mathrm{t})\right) \in \mathrm{R}^{2}$ and $\alpha(\mathrm{t}) \in \mathrm{B}$. The following differential equations represent the dynamics of finished product stocks:

$$
\begin{cases}\dot{x}_{1}(t)=\sum_{j=1}^{m} u^{1 j}(t)-d_{1}, & x_{1}(0)=x_{1}^{0} \\ \dot{x_{2}}(t)=\sum_{j=1}^{m} u^{2 j}(t)+U_{s t}^{R}+Q_{s t}^{U}(t)-d_{2}, & x_{2}(0)=x_{2}^{0}\end{cases}
$$


Where $\mathrm{x}_{1}^{0}$ and $\mathrm{x}_{2}^{0}$ designate the initial level of in ventory of products $\mathrm{P}_{1}$ and $\mathrm{P}_{2}$, respectively. The production rates at every moment must satisfy the capacity constraint of the system given by:

$$
0 \leq \mathrm{u}^{\mathrm{ij}}(\mathrm{t}) \leq \mathrm{U}_{\max }^{\mathrm{ij}} * \alpha_{\mathrm{j}}(\mathrm{t}), \forall \mathrm{i} \in \mathrm{I} \text { and } \mathrm{j} \in \mathrm{J}
$$

Given the subcontracting of the product $\mathrm{P}_{2}$, the production capacity of the system increases in order to meet the customer demand. The overall feasibility constraint is formulated as follows:

For the product $\mathrm{P}_{1}$ :

$$
\sum_{j=1}^{m}\left(U_{\text {max }}^{1 \mathrm{j}} * \frac{\mathrm{MTBF}_{\mathrm{j}}}{\mathrm{MTBF}_{\mathrm{j}}+\mathrm{MTTR}_{\mathrm{j}}}\right) \geq \mathrm{d}_{1}
$$

For the product $\mathrm{P}_{2}$ :

$$
\left(\left(1-\frac{\mathrm{d}_{1}}{\sum_{\mathrm{j}=1}^{\mathrm{m}} \mathrm{U}_{\text {max }}^{1 \mathrm{j}}}\right) * \sum_{\mathrm{j}=1}^{\mathrm{m}}\left(\mathrm{U}_{\max }^{2 \mathrm{j}} * \frac{\mathrm{MTBF}_{\mathrm{j}}}{\mathrm{MTBF}_{\mathrm{j}}+\mathrm{MTTR}_{\mathrm{j}}}\right)\right)+\mathrm{U}_{\mathrm{st}}^{\mathrm{R}}+\mathrm{Q}_{\mathrm{st}}^{\mathrm{U}}(\mathrm{t}) \geq \mathrm{d}_{2}
$$

Equation (4) takes into account the prioritization of the product $\mathrm{P}_{1}$ which cannot be provided from external sources (the subcontracting). This prioritization is represented by " $\mathrm{d}_{1} / \sum_{\mathrm{j}=1}^{\mathrm{m}} \mathrm{U}_{\max }^{1 \mathrm{j}}$ ". The latter corresponds to the usage proportion of the production capacity of the facilities which allow the satisfaction of the demand $d_{1}$. Our decision variables are the production rates $\left(\mathrm{u}^{\mathrm{i} 1}(\mathrm{t}), \ldots, \mathrm{u}^{\mathrm{im}}(\mathrm{t})\right)$ of facilities $\mathrm{M}_{1}, \mathrm{M}_{2}, \ldots \mathrm{M}_{\mathrm{m}}$, the rate of regular $\left(\mathrm{U}_{\mathrm{st}}^{\mathrm{R}}\right)$ and the urgent subcontracting orders $\left(Q_{s t}^{U}(t)\right)$. It should be noted that $Q_{s t}^{U}(t)$ was used in order to restore the level of safety stocks where applicable. When taking into account (2)-(4), for each mode of $\alpha(t) \in B$, $i \in\{1,2\}$ and $j \in\{1, \ldots, m\}$, the acceptable decisions are presented as follows:

$$
\Gamma=\left\{\begin{array}{c}
\left(\mathrm{u}^{11}(\mathrm{t}), \ldots, \mathrm{u}^{1 \mathrm{~m}}(\mathrm{t}), \mathrm{u}^{21}(\mathrm{t}), \ldots, \mathrm{u}^{2 \mathrm{~m}}(\mathrm{t}), \mathrm{U}_{\mathrm{st}}^{\mathrm{R}}, \mathrm{Q}_{\mathrm{st}}^{\mathrm{U}}(\mathrm{t})\right): 0 \leq \mathrm{u}^{\mathrm{ij}}(\mathrm{t}) \leq \mathrm{U}_{\max }^{\mathrm{ij}} * \alpha_{\mathrm{j}}(\mathrm{t}), \\
\left(\mathrm{d}_{1} * \mathrm{AR}+\mathrm{d}_{2}-\sum_{\mathrm{j}=1}^{\mathrm{m}} \mathrm{U}_{\max }^{2 \mathrm{j}}\right) \leq \mathrm{U}_{\mathrm{st}}^{\mathrm{R}} \leq \mathrm{d}_{2}, \sum_{\mathrm{j}=1}^{\mathrm{m}}\left(\mathrm{U}_{\max }^{1 \mathrm{j}} * \frac{\mathrm{MTBF}_{\mathrm{j}}}{\mathrm{MTBF}_{\mathrm{j}}+\mathrm{MTTR}_{\mathrm{j}}}\right) \geq \mathrm{d}_{1}, \\
\quad\left(\left(1-\frac{\mathrm{d}_{1}}{\sum_{\mathrm{j}=1}^{\mathrm{m}} \mathrm{U}_{\text {max }}^{1 \mathrm{j}}}\right) * \sum_{\mathrm{j}=1}^{\mathrm{m}}\left(\mathrm{U}_{\mathrm{max}}^{2 \mathrm{j}} * \frac{\mathrm{MTBF}_{\mathrm{j}}}{\mathrm{MTBF}_{\mathrm{j}}+\mathrm{MTTR}_{\mathrm{j}}}\right)\right)+\mathrm{U}_{\mathrm{st}}^{\mathrm{R}}+\mathrm{Q}_{\mathrm{st}}^{\mathrm{U}}(\mathrm{t}) \geq \mathrm{d}_{2}
\end{array}\right\}
$$

Where AR is the aggregation ratio converting product 1 into product 2 from a capacity point of view. $A R=\frac{\mathrm{U}_{\max }^{2 \mathrm{j}}}{\mathrm{U}_{\max }^{1 \mathrm{j}}}$ 
A facility failure may incur costs which are added to those for production, subcontracting, inventory and storage space. Such costs are associated with unmet customer demand, and include penalties generated by insufficient stock, and even the loss of customers. The problem is of finding an acceptable control policy in order to minimize the cost function $\mathrm{J}($.) by respecting the customer satisfaction constraint.

$$
J(.)=c^{e}\left(Z_{1}, Z_{2}\right)+E\left\{\int_{0}^{\infty} e^{-\rho t} g(.) d t\right\}
$$

In addition to inventory costs $\left(\mathrm{c}_{\mathrm{i}}^{+}\right)$, the model considers storage space cost $\left(\mathrm{c}^{\mathrm{e}}\right)$, depending on the storage capacity required to maintain the two finished products. The cost penalizes the storage space, and not the conservation actions targeting finished products [28]. It represents the depreciation (investment / lifetime) of the equipment considered [29] (we assume a linear depreciation). It is in fact a step $\cos ^{(2)}$ in the form of an average cost per unit of time. The discount rate is denoted by $\rho$ and the instantaneous cost function by $g($.$) . This function is defined$ at the instant $t$ as follows:

$$
g(X, U)=\sum_{i=1}^{2}\left(c_{i}^{+} x_{i}^{+}(t)+c_{i}^{-} x_{i}^{-}(t)\right)+\sum_{i=1}^{2} \sum_{j=1}^{m}\left(c_{i j}^{p} u^{i j}(t)\right)+\left(c_{s t}^{R} U_{s t}^{R}\right)+\left(c_{s t}^{u} Q_{s t}^{U}(t)\right)
$$

Where $\mathrm{U}$ denotes the vector of production rates, regular subcontracting rate and urgent subcontracting orders, $\mathrm{X}$ is the vector of the inventory levels (or of the shortage) of both products. Thus,

$$
\left\{\begin{array}{l}
x_{i}^{+}(t)=\max \left(0, x_{i}(t)\right) \\
x_{i}^{-}(t)=\max \left(-x_{i}(t), 0\right)
\end{array}\right.
$$

The production cost $\left(c_{2 j}^{p}, j \in\{1, \ldots, m\}\right)$ and the subcontracting cost $\left(c_{s t}^{R}\right.$ and $\left.c_{s t}^{u}\right)$ of product $P_{2}$ must satisfy the following inequality:

$$
0<c_{2 j}^{\mathrm{p}}<\mathrm{c}_{\mathrm{st}}^{\mathrm{R}}<\mathrm{c}_{\mathrm{st}}^{\mathrm{u}}, \forall \mathrm{j} \in \mathrm{J}
$$

As mentioned above, the problem of production planning is considered to establish an acceptable control policy $\left(\mathrm{U}^{*}\right) \in \Gamma$. This will lead to the minimization of the updated total average cost (6), while respecting the customer satisfaction specification on the one hand, and considering

\footnotetext{
${ }^{2}$ Fixed cost that increases to a new level in step with the significant changes in Tank's capacity $\left(\mathrm{Z}_{1}\right.$ and $\left.\mathrm{Z}_{2}\right)$
} 
constraints (1)-(5) on the other. This policy constitutes a feedback that determines the amount of subcontracting and of production of each facility, depending on the state of the system. The value function of the optimization problem is described by the following function:

$$
v(X)=\inf _{\left(u^{i j}, U_{s t}^{R}, Q_{s t}^{u}\right) \in \Gamma} J\left(X, \alpha(t), u^{i j}(t), U_{s t}^{R}, Q_{s t}^{U}(t)\right), i \in\{1,2\}, j \in\{1,2, \ldots, m\}
$$

The determination of the properties of the function (8) leads to the optimality conditions described by the Hamilton-Jacobi Bellman (HJB) equations. However, the analytical solution of these equations is only possible in specific cases, namely, those involving simple production systems that are analyzed using Markov chains [30]. In the following sections, we propose a control policy which simultaneously combines the production and the subcontracting planning of the production system. We also present an experimental solution approach based on experimental design, analysis of variance, response surface methodology, and simulation modeling in order to generate the optimal control parameters of the proposed policy.

\subsection{General joint production/subcontracting control policy}

The proposed general control policy, as in Wang and Chan who treated the prioritization in the case of one machine and multiple products [31], takes into account the priority given to the innovative product $\mathrm{P}_{1}$ whose company is the only producer. The manufacturing of this product depends only on its inventory level with respect to threshold $Z_{1}$ (see equation (9)). The threshold $Z_{i}, i \in\{1,2\}$ defines the storage space capacity of each type of product $P_{i}$. Using the term " $\sum_{\mathrm{j}=1}^{\mathrm{m}}\left(\mathrm{U}_{\max }^{2 \mathrm{j}} * \alpha_{\mathrm{j}}(\mathrm{t})\right)-\mathrm{d}_{1} * \mathrm{AR}$ ", only the remaining production capacity is allocated to the product $\mathrm{P}_{2}$ (see equation (10)). However, if this capacity is insufficient to meet demand $\mathrm{d}_{2}$, the subcontracting is thus used to ensure the satisfaction of the demand $d_{2}$ and to face several random phenomena such as failures and repairs time (see equations (10) - (11)). Both regular and urgent subcontracting are considered in the proposed control policy (see (11)). The first is a fixed rate whose value must be optimized. While the second one is composed of orders which are activated in order to reduce the risk of shortages. We thus defined the threshold $S_{Q}$ as the inventory level of product $\mathrm{P}_{2}$ at which urgent orders are launched. We integrate urgent 
subcontracting, which depends on a random transportation delay (TD) into the proposed model based on Mourani et al. [32] whom considered the transportation delay of the production.

Let $U_{s t}(t)$ be the set of decision variables related to subcontracting and $\left(u^{1}(t), u^{2}(t)\right)$ the decision variables related to the production rate of part types $\mathrm{P}_{1}$ and $\mathrm{P}_{2}$, respectively. The structure of the proposed control policy, called the general joint production/subcontracting control policy, is expressed by equations (9)-(11):

- For the product $\mathrm{P}_{1}$ :

$\mathrm{u}^{1}(\mathrm{t}): \begin{cases}\sum_{\mathrm{j}=1}^{\mathrm{m}}\left(\mathrm{U}_{\max }^{1 \mathrm{j}} * \alpha_{\mathrm{j}}(\mathrm{t})\right) & \text { if }\left(\mathrm{x}_{1}(\mathrm{t})<\mathrm{Z}_{1}\right) \\ \min \left(\mathrm{d}_{1}, \sum_{\mathrm{j}=1}^{\mathrm{m}}\left(\mathrm{U}_{\max }^{1 \mathrm{j}} * \alpha_{\mathrm{j}}(\mathrm{t})\right)\right) & \text { if }\left(\mathrm{x}_{1}(\mathrm{t})=\mathrm{Z}_{1}\right) \\ 0 & \text { otherwise }\end{cases}$

- For the product $\mathrm{P}_{2}$ :

$\mathrm{u}^{2}(\mathrm{t}):\left\{\begin{array}{lc}\sum_{\mathrm{j}=1}^{\mathrm{m}}\left(\mathrm{U}_{\max }^{2 \mathrm{j}} * \alpha_{\mathrm{j}}(\mathrm{t})\right) & \text { if }\left(\mathrm{x}_{1}(\mathrm{t})>\mathrm{Z}_{1}\right) \text { and }\left(\mathrm{x}_{2}(\mathrm{t})<\mathrm{Z}_{2}\right) \\ \max \left(0, \sum_{\mathrm{j}=1}^{\mathrm{m}}\left(\mathrm{U}_{\max }^{2 \mathrm{j}} * \alpha_{\mathrm{j}}(\mathrm{t})\right)-\mathrm{d}_{1} * A R\right) & \text { if }\left(\mathrm{x}_{1}(\mathrm{t})=\mathrm{Z}_{1}\right) \text { and }\left(\mathrm{x}_{2}(\mathrm{t})<\mathrm{Z}_{2}\right) \\ \min \left(\mathrm{d}_{2}-\mathrm{U}_{\mathrm{st}}^{\mathrm{R}}, \sum_{\mathrm{j}=1}^{\mathrm{m}}\left(\mathrm{U}_{\max }^{2 \mathrm{j}} * \alpha_{\mathrm{j}}(\mathrm{t})\right)\right) & \text { if }\left(\mathrm{x}_{1}(\mathrm{t})>\mathrm{Z}_{1}\right) \text { and }\left(\mathrm{x}_{2}(\mathrm{t})=\mathrm{Z}_{2}\right) \\ \min \left(\mathrm{d}_{2}-\mathrm{U}_{\mathrm{st}}^{\mathrm{R}}, \max \left(0, \sum_{\mathrm{j}=1}^{\mathrm{m}}\left(\mathrm{U}_{\max }^{2 \mathrm{j}} * \alpha_{\mathrm{j}}(\mathrm{t})\right)-\mathrm{d}_{1} * A R\right)\right) & \text { if }\left(\mathrm{x}_{1}(\mathrm{t})=\mathrm{Z}_{1}\right) \text { and }\left(\mathrm{x}_{2}(\mathrm{t})=\mathrm{Z}_{2}\right) \\ 0 & \text { otherwise }\end{array}\right.$

$U_{s t}(t): \begin{cases}U_{s t}^{R}+Q_{s t}^{U}(t+T D) & \text { if } x_{2}(t)=S_{Q} \\ U_{s t}^{R} & \text { otherwise }\end{cases}$

With,

$$
\mathrm{U}_{\mathrm{st}}^{\mathrm{R}}+\mathrm{Q}_{\mathrm{st}}^{\mathrm{U}}(\mathrm{t})+\left[\left(1-\frac{\mathrm{d}_{1}}{\sum_{\mathrm{j}=1}^{\mathrm{m}} \mathrm{U}_{\max }^{1 \mathrm{j}}}\right) *\left(\sum_{\mathrm{j}=1}^{\mathrm{m}}\left(\mathrm{U}_{\text {max }}^{2 \mathrm{j}} * \frac{\mathrm{MTBF}_{\mathrm{j}}}{\mathrm{MTBF}_{\mathrm{j}}+\mathrm{MTTR}_{\mathrm{j}}}\right)\right)\right] \geq \mathrm{d}_{2}
$$

Recall that " $\sum_{\mathrm{j}=1}^{\mathrm{m}}\left(\mathrm{U}_{\max }^{2 \mathrm{j}} * \alpha_{\mathrm{j}}(\mathrm{t})\right)-\mathrm{d}_{1} * \mathrm{AR}$ " integrated in equation (10) represents the prioritization allocated to the product $P_{1}$. The term " $d_{2}-U_{s t}^{R}$ " presented in (10) corresponds to the usage of the production capacity of the $\mathrm{m}$ facilities which allow to adjust production of the 
product $\mathrm{P}_{2}$ to demand $\mathrm{d}_{2}$ and to avoid overproduction. The urgent subcontracting orders considered in (11) are activated when the inventory level of product $\mathrm{P}_{2}$ decreases and reaches the threshold $\mathrm{S}_{\mathrm{Q}}\left(\mathrm{x}_{2}(\mathrm{t})=\mathrm{S}_{\mathrm{Q}}\right)$, where $\mathrm{S}_{\mathrm{Q}}$ is the activation threshold of rush orders and $\mathrm{S}_{\mathrm{Q}} \leq \mathrm{Z}_{2}$.

To illustrate the effectiveness of the joint production/subcontracting control policy and the solution approach proposed in this study, the results will be compared to those of Dror et al. [1] in the case of two production facilities (see sections 6.2,7 and 8).

\section{The experimental solution approach}

The solution approach adopted in order to solve this problem is based on that proposed by Gharbi et al. [24], and on a combination of the simulation modeling and statistical optimization methods. The experimental solution approach consists of the following main steps:

- Step 1: Mathematical definition of the problem

As presented in section 2.2, the problem is formulated analytically in order to understand the dynamics of the production system in terms of its states, as well as to define the expression of the average total cost. It should be noted that customer satisfaction is considered as a constraint in the optimization of the control parameters that minimize the average total cost.

- Step2: Simulation model

The simulation model uses the proposed general joint production/subcontracting control policy, as described in section 2.3, as an input for conducting experiments and evaluating the production system performance. The model considers two response variables: the total cost and the level of customer satisfaction. The simulation model will be presented in section 4 .

- Step 3: Experimental design and response surface methodology

The general simulation model was applied to the joint production/subcontracting control policy. The experimental design determines the main factors $\left(Z_{1}, Z_{2}, U_{s t}^{R}, Q_{s t}^{U}(t)\right.$, and $\left.S_{Q}\right)$ and their interactions, which have a significant effect on the output (i.e., the cost and the customer satisfaction). Subsequently, the response surface methodology will be used in order to define the relationship between each of the response variables, the main factors and their significant 
interactions. The resulting model is then optimized in order to determine the best combination of parameters of the control policy that minimize the total cost while respecting the required customer satisfaction level.

\section{Simulation model}

In this work, we use the "Flow Process" module of the ARENA simulator and subroutines written in the VBA language in order to model the dynamics of the production system. The "Flow Process" module is based on a combined approach of continuous and discrete events of the ARENA simulator. Evidently, the choice of the "Flow Process" module is based not only on the large amount of finished products at stake, the continuity of the workflow and the discrete nature of the dynamics of the manufacturing system, but also on its ability to dramatically shorten the execution time when compared to the purely discrete models [33]. Different offline separate replications of our simulation number are executed in order to determine the necessary time for the system to reach its steady state. The value found approximately corresponds to 300,000 days but we used 600,000 days which constitutes a cushion. Note that the execution time in this case is equal to 12 seconds.

The simulation model diagram is presented in Figure 2. It is composed of several networks interacting with each other and that each one executes specific tasks (production, subcontracting, repair interventions, etc.). After the initialization (1) of its variables (demand rates, subcontracting rates, production rates, simulation time, etc.), the simulation model operates on the basis of a control policy (2) ((9)-(11)) and is executed through the ARENA simulation software in order to reproduce the system dynamics and evaluate its performance. The block Sensors (3) continuously monitors the inventories of both finished products and sends signals after each triggering to the control policy block (2) each time a threshold $0, \mathrm{Z}_{1}, \mathrm{Z}_{2}$ and $\mathrm{S}_{\mathrm{Q}}$ is reached. Then, the control policy block decides, through the opening and closing actions of the valves, what type and how much of the finished products should be manufactured (4) as well as the value of both regular and urgent subcontracting orders (5). Note that $Z_{1}$ and $Z_{2}$ represent the capacity of tanks and each one is dedicated to one part type. The block (6) updates the inventory level of both products $\left(\mathrm{x}_{\mathrm{i}}\right.$, $\forall i \in\{1,2\})$ in the tanks whenever a quantity of the finished products is manufactured or subcontracted $\left(\mathrm{x}_{\mathrm{i}} \leq \mathrm{Z}_{\mathrm{i}}, \forall \mathrm{i} \in\{1,2\}\right)$, or when a client request arrives. When a product type is not 
backlogged, its production increases its inventory level; otherwise, it merely satisfies the overdue demand, which decreases the stock-out.

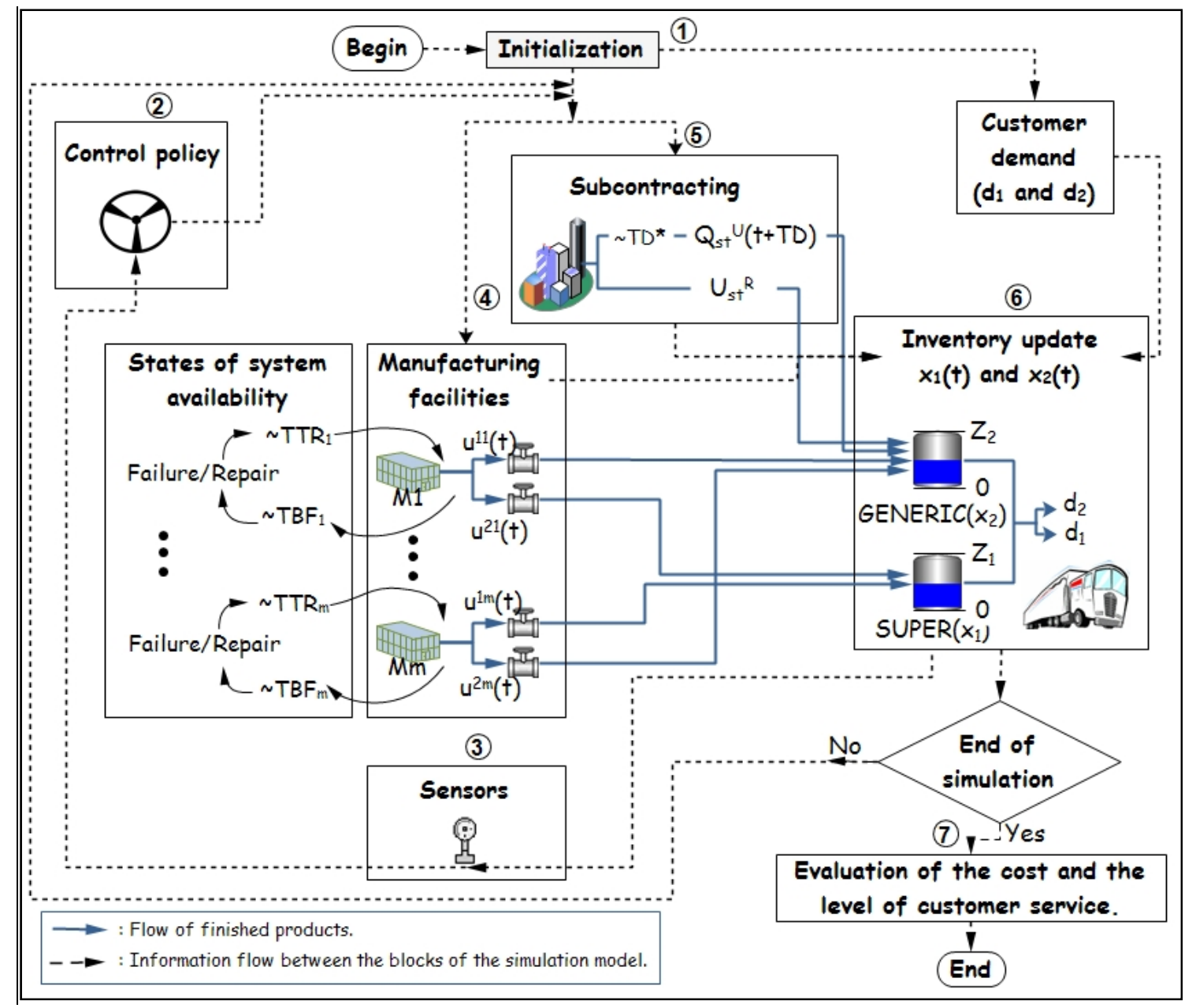

Figure 2. Diagram of the simulation model

At the end of the simulation (7) all the information needed in order to calculate the average value of the total cost incurred (6), as well as the percentage of orders fulfilled by the part types, from the stocks of finished goods without any delay. Customer satisfaction is linked to the availability of finished products. Thus, for each part type $P_{i}, i=1,2$, the customer satisfaction is calculated as follows:

$$
\mathrm{S}\left(\mathrm{P}_{\mathrm{i}}\right)=1-\left[\left(\sum_{\mathrm{i}} \mathrm{T}_{\mathrm{i}}^{\mathrm{NS}}\right) / \mathrm{T}_{\mathrm{Sim}}\right]
$$

Where $T_{i}^{N S}$ is the time during which the requests of the product $P_{i}$ are not satisfied on time, and $\mathrm{T}_{\text {sim }}$ represents the duration of the simulation. We note that the constraint of achieving a service level of $99.5 \%$ is equivalent to $S\left(P_{i}\right) \geq 99.5 \% \forall i \in\{1,2\}$. 


\section{Control policy and heuristic approach proposed by Dror et al. [1] (HEU)}

Using two production facilities, Dror et al. [1] consider that the manufacturing system is complex and apply a heuristic method to solve the problem based on simplifying assumptions. Their goal consists in establishing a control policy which helps minimize safety stocks and storage requirements. This should be done while respecting the client satisfaction constraint in order to ensure a specific level of customer service greater than or equal to $99.5 \%$. The customer satisfaction depends on the availability of finished products. Thus, a customer is considered satisfied if the demand is met without delay; otherwise, the customer is not satisfied. Table 1 shows the production capacity of both facilities and the daily customer demand amount for each part type. Note that since the products $\mathrm{P}_{1}$ and $\mathrm{P}_{2}$ have very similar chemical characteristics, the maximum production rates of the products $P_{1}\left(U_{\text {max }}^{1 j}\right)$ and $P_{2}\left(U_{\text {max }}^{2 j}\right)$ at the facility $M_{j}, j \in\{1,2\}$ are identical $\left(\mathrm{U}_{\max }^{11}=\mathrm{U}_{\max }^{21}=3200 \mathrm{st} /\right.$ day, $\mathrm{U}_{\max }^{12}=\mathrm{U}_{\max }^{22}=1500$ st $/$ day $)$; so $\mathrm{AR}=1$.

Table 1. Demand and production capacity parameters

\begin{tabular}{|c|c|c|c|c|}
\hline \multicolumn{2}{|c|}{ Demand $\left(\mathrm{st}^{*} /\right.$ day $)$} & \multicolumn{2}{|c|}{ Production capacity (st*/day) } & \multirow{3}{*}{$\begin{array}{l}\text { Portion of the demand met by } \\
\text { subcontracting } U_{s t}^{R}(t)(s t * / \text { day })\end{array}$} \\
\hline $\mathrm{d}_{1}$ & $\mathrm{~d}_{2}$ & $\mathrm{U}_{\max }^{\mathrm{i} 1}$ & $\mathrm{U}_{\max }^{\mathrm{i} 2}$ & \\
\hline 2710 & 2540 & 3200 & 1500 & \\
\hline \multicolumn{2}{|c|}{5250} & \multicolumn{2}{|c|}{4700} & $550(5250-4700)$ \\
\hline
\end{tabular}

It is worth noting that the control policy proposed by Dror et al. [1] represents a simplification of the general control policy expressed in section 2.3. Assuming that the cost of subcontracting is high, compared to that for production, these authors set the regular subcontracting rate at a value of $550 \mathrm{st} /$ day which represents the portion of the demand that cannot be produced in the facilities due to a lack of capacity (Table 1). Because of breakdowns, the demand cannot be satisfied at all. For that reason, Dror et al. [1] took into consideration urgent subcontracting, which is activated upon failure occurrence of one or more facilities. Urgent orders which concern only product $\mathrm{P}_{2}$ depend on the capacity of the broken down facility $\left(\mathrm{M}_{1}\right.$ and/or $\left.\mathrm{M}_{2}\right)$ and the time of the repair activity. They are intended to replace the production capacity which was lost during repair actions and to restore the inventory level of buffer stocks at the end of remedial actions. The 
entire production capacity is diverted to the restoration of the inventory level of product $\mathrm{P}_{1}$ since the company in question is the only producer of product $\mathrm{P}_{1}$.

After taking into account the data of the problem presented in Section 2 and Table 1, the control policy of the production and subcontracting was formulated by equations (9), (13)-(15).

- For the product $\mathrm{P}_{2}$ :

$$
\begin{aligned}
& \mathrm{u}^{2}(\mathrm{t})= \begin{cases}\sum_{\mathrm{j}=1}^{2}\left(\mathrm{U}_{\max }^{2 \mathrm{j}} * \alpha_{\mathrm{j}}(\mathrm{t})\right) & \text { if }\left(\mathrm{x}_{1}(\mathrm{t})>\mathrm{Z}_{1}\right) \text { and }\left(\mathrm{x}_{2}(\mathrm{t}) \leq \mathrm{Z}_{2}\right) \\
\sum_{\mathrm{j}=1}^{2}\left(\mathrm{U}_{\max }^{2 \mathrm{j}} * \alpha_{\mathrm{j}}(\mathrm{t})\right)-\mathrm{d}_{1} & \text { if }\left(\mathrm{x}_{1}(\mathrm{t})=\mathrm{Z}_{1}\right) \text { and }\left(\mathrm{x}_{2}(\mathrm{t}) \leq \mathrm{Z}_{2}\right) \\
0 & \text { otherwise }\end{cases} \\
& \mathrm{U}_{\mathrm{st}}^{\mathrm{R}}=\left(\mathrm{d}_{1}+\mathrm{d}_{2}\right)-\left(\mathrm{U}_{\max }^{21}+\mathrm{U}_{\max }^{22}\right)=550 \mathrm{st} / \text { day }
\end{aligned}
$$

And

$$
\mathrm{Q}_{\mathrm{st}}^{\mathrm{U}}(\mathrm{t})= \begin{cases}\mathrm{U}_{\max }^{21} \mathrm{st} / \text { day } & \text { if } \alpha_{1}(\mathrm{t})=0 \text { and } \alpha_{2}(\mathrm{t})=1 \\ \mathrm{U}_{\max }^{22} \text { st/day } & \text { if } \alpha_{1}(\mathrm{t})=1 \text { and } \alpha_{2}(\mathrm{t})=0 \\ \mathrm{U}_{\max }^{21}+\mathrm{U}_{\max }^{22} \text { st } / \text { day } & \text { if } \alpha_{1}(\mathrm{t})=0 \text { and } \alpha_{2}(\mathrm{t})=0 \\ 0 \text { st/day } & \text { if } \alpha_{1}(\mathrm{t})=1 \text { and } \alpha_{2}(\mathrm{t})=1\end{cases}
$$

Given the complexity of this problem, Dror et al. [1] adopted several approximations and hypotheses to reduce the difficulty of modeling:

- The mean time between failures (MTBF) and the mean time to repair (MTTR) facilities follow the exponential distribution (constant failure rate). The average time between two consecutive failures is equal to 6.4 months.

- No failure is allowed during the rebuilding of safety stocks.

- The delivery time for urgent subcontracting orders is constant.

- The setup time and cost are negligible.

- The analysis is limited to the customer satisfaction criterion and the incurred costs are not considered at all. 
The solution obtained by Dror et al. [1] consists in constructing two storage spaces with a capacity of 38,000 st and 34,000 st for the finished products $\mathrm{P}_{1}$ and $\mathrm{P}_{2}$, respectively. However, this solution is the result of a simplified approach, and is based on common sense, and relies mainly on the $99^{\text {th }}$ percentile of the repair-time distribution to calculate the inventories of both finished products. These inventories are needed to ensure the immediate satisfaction of customer demand if a facility fails, until the company can receive external supply. Furthermore, Dror et al. [1] roughly take account of possible failures of both facilities at the same time. They calculated that the probability that both facilities are down at the same time is approximately equal to 0.18 percent which is equivalent to one day in an 18 month interval. Therefore, an additional amount of finished product inventory equal to one day of operation is roughly estimated in order to compensate for the situation where two facilities break down simultaneously. Based on heuristic solution approach, the Dror's solution does not guarantee the minimization of storage needs.

\section{Experimental solution approach based on Dror's control policy (EXP_S)}

In this section, the experimental solution approach based on simulation modeling, design of experiments, analysis of variance and response surface methodologies proposed in section 3, will first be applied to Dror's restrictive control policy presented in section 5. Note that the number of the production facilities considered in the following is limited to two as adopted in [1]. The main objective of this approach is to study the actual behavior of the production system and to deduce the optimal parameters of the control policy defined in section $5\left(Z_{1}\right.$ and $\left.Z_{2}\right)$. These control parameters minimize the total incurred cost (6), while respecting the constraint of customer satisfaction. Thus, decision makers will be able to take into account the cost factors and customer satisfaction simultaneously. The use of this approach has allowed the relaxation of several assumptions made by Dror et al. [1]:

- According to the historical occurrences of failures, times between failures of the two facilities follow a Weibull distribution whose shape and scale parameters are equal to 1.53 and 6.72 , respectively. The mean time to failure equals 6.4 months. The repair time distribution also follows a Weibull distribution with a shape and scale parameters that are equal to 2.09 and 9.47 , respectively. The mean time to repair equals 8.35 days.

- The two manufacturing facilities can fail simultaneously without any restriction. 
- As in real situations, we consider that failures may occur before the end of the total restoration of buffer stocks.

- The delivery time for urgent subcontracting is a random variable. We represent it through a normal distribution with an average of 14 days, as in Dror et al. [1] and we consider a standard deviation of 3 days.

- We consider different costs associated with inventory holding $\left(\mathrm{c}_{1}^{+} ; \mathrm{c}_{2}^{+}\right)$, storage space $\left(c^{\mathrm{e}}\right)$, inventory backlogs $\left(\mathrm{c}_{1}^{-} ; \mathrm{c}_{2}^{-}\right)$, production $\left(\mathrm{c}_{1}^{\mathrm{p}} ; \mathrm{c}_{2}^{\mathrm{p}}\right)$, and regular and urgent subcontracting $\left(\mathrm{c}_{\mathrm{st}}^{\mathrm{R}} ; c_{\mathrm{st}}^{\mathrm{u}}\right)$.

The experimental approach proposed in section 3 is tailored to Dror's restrictive control policy defined in section 5 in order to deduce the optimal control parameters $\left(Z_{1}, Z_{2}\right)$.

\subsection{Validation of the simulation model}

We consider the context of the pharmaceutical company studied by Dror et al. [1] as a base case to validate the proposed simulation model and to illustrate the concepts developed in this article. In addition to the problem data defined in section 5 [1], the parameter values of the cost function (6) were chosen so that $\mathrm{c}_{\mathrm{i}}^{+} \ll \mathrm{c}_{\mathrm{i}}^{-}$and $\mathrm{c}_{2 \mathrm{j}}^{\mathrm{p}}<\mathrm{c}_{\mathrm{st}}^{\mathrm{R}}<\mathrm{c}_{\mathrm{st}}^{\mathrm{u}}, \forall \mathrm{i}, \mathrm{j} \in\{1,2\}^{2}$. Table 2 summarizes the values of these cost parameters. Recall that Dror et al. [1] ignored in their work the production, the subcontracting, the inventory and the backlog cost parameters. $\forall \mathrm{j} \in\{1,2\}$ :

Table 2. Values of system cost parameters

\begin{tabular}{|c|cccc|}
\hline Parameters & $\left(\mathrm{c}_{1}^{+} ; \mathrm{c}_{2}^{+}\right)$ & $\left(\mathrm{c}_{1}^{-} ; \mathrm{c}_{2}^{-}\right)$ & $\left(\mathrm{c}_{1 \mathrm{j}}^{\mathrm{p}} ; \mathrm{c}_{2 \mathrm{j}}^{\mathrm{p}}\right)$ & $\left(\mathrm{c}_{\mathrm{st}}^{\mathrm{R}} ; \mathrm{c}_{\mathrm{st}}^{\mathrm{u}}\right)$ \\
\hline Values & $(1 ; 1)$ & $(80 ; 80)$ & $(30 ; 30)$ & $(60 ; 100)$ \\
\hline
\end{tabular}

To validate the simulation model, a graphical representation of the variation in production/subcontracting rates and inventory levels of finished products was generated (Figure3). The system simulation was performed for $Z_{1}=12,000$ st and $Z_{2}=9,000$ st. From Figure 3 , the inventory level of both finished products increases to their critical thresholds $\left(Z_{1}\right.$ and $\mathrm{Z}_{2}$ ) and stabilize at these values (1). This stability is possible if quantities of product $\mathrm{P}_{2}$ are received on a regular basis $\left(\mathrm{U}_{\mathrm{st}}^{\mathrm{R}}\right)$ from external sources (2), in order to address a lack of capacity 
in relation to customer demand. During the failure of one or more Facilities (3): failure of M1), the stock level decreases until the end of the repair activities and/or the urgent subcontracting reception of the quantity of product $\mathrm{P}_{2}$. In fact, when a facility is under repairs, urgent orders are automatically launched in order to obtain additional quantities of product $\mathrm{P}_{2}$ (4). These quantities depend on the capacity of the failed facility (see (15)), and of course, the length of the repair activities. However, when facility M2 fails (5) the safety stock of product $\mathrm{P}_{2}$ is used in order to satisfy the demand, which is why the corresponding inventory level decreases.

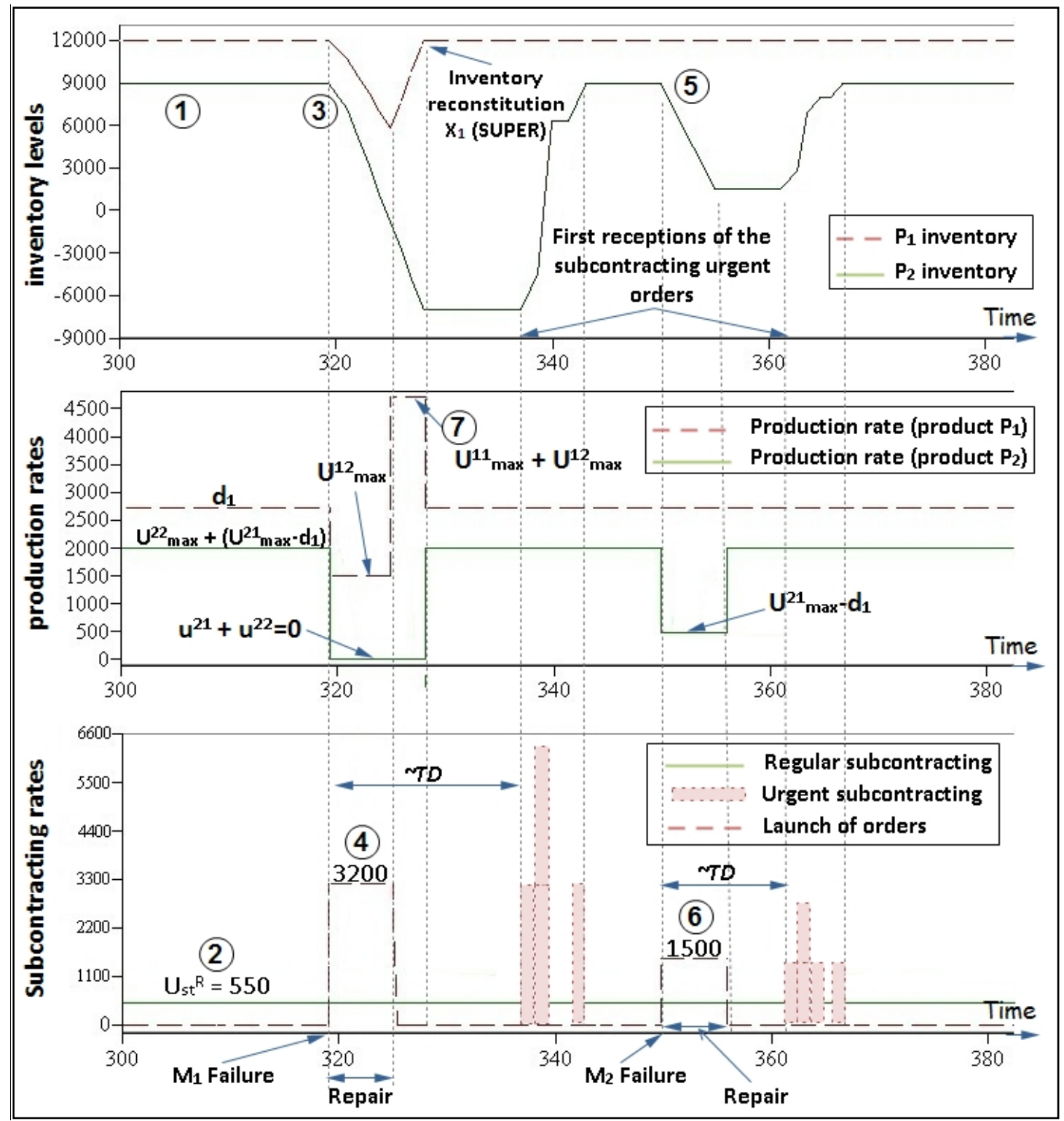

Figure 3. Variation in inventories, subcontracting rates and production rates of both finished products $\left(Z_{1}=12,000\right.$ st and $\left.Z_{2}=9,000 \mathrm{st}\right)$ 
On the other hand, the inventory level of product $\mathrm{P}_{1}$ remains stable. This is explained by the fact that the facility $M_{1}$, which is still in use, is able to satisfy the demand $d_{1}$ along with a small amount of product $\mathrm{P}_{2}$. Urgent orders are also activated in order to restore the inventory level of product $\mathrm{P}_{2}$ after a random delivery time (6). Because the company is the only manufacturer of product $\mathrm{P}_{1}$, if the inventory level of the product is lower than the critical threshold $\left(\mathrm{Z}_{1}\right)$, any facility in its operational state is used at its maximum capacity in order to produce this product (7). Such behaviors occur until the end of the simulation, and they show that the simulation model adequately represents the control policy described in section 5 .

\subsection{Experimental design and response surface methodology}

This section presents the methodology adopted to optimize the parameters of the control policy. The objectives are: 1) to determine the relationship between the output variables of the system response (i.e., the cost and the customer satisfaction), the control factors $\left(Z_{1}\right.$ and $\left.Z_{2}\right)$ as well as their interactions, which have a significant effect on the output variables; 2) to calculate the optimal values of the control policy parameters (control factors) which minimize the total cost considering the customer satisfaction constraint for each type of finished products.

Based on the work of Gharbi and Kenné [32], we assume that the value function (8) is convex, and we adopt a full factorial design with 2 factors at 3 levels each $\left(3^{2}\right)$ [24]. The full factorial of such a plan is often used for a model that assigns a small number of factors. It gives more accurate results since each interaction is estimated separately. Five replicates were performed for each combination of factors, meaning therefore that $45\left(3^{2} * 5\right)$ simulations were performed. The duration of the simulation is equal to $T_{\text {sim }}=600,000$ days, which is long enough to reach the steady state. The common random number technique is also used in order to reduce the variability in the simulation results from one experiment to another [35]. From some preliminary simulation experiments, the levels of the independent variables were established, such as in Table 3. 
Table 3. Levels of the independent variables

\begin{tabular}{|ccccc|}
\hline Factor & Lower level & Center & Upper level & Descriptions \\
\hline $\mathbf{Z}_{\mathbf{1}}$ & 2,000 & 10,000 & 18,000 & Stock level of the product $\mathrm{P}_{1}$ \\
\hline $\mathbf{Z}_{\mathbf{2}}$ & 17,000 & 23,500 & 30,000 & Stock level of the product $\mathrm{P}_{2}$ \\
\hline
\end{tabular}

A multi-factorial analysis of variance (ANOVA) was performed using the statistical software, Statgraphics. Figure 4 shows the effects of independent variables $\left(Z_{1}\right.$ and $\left.Z_{2}\right)$, their interactions, and their quadratic effect on the response variables (cost and customer satisfaction for each type of finished product).

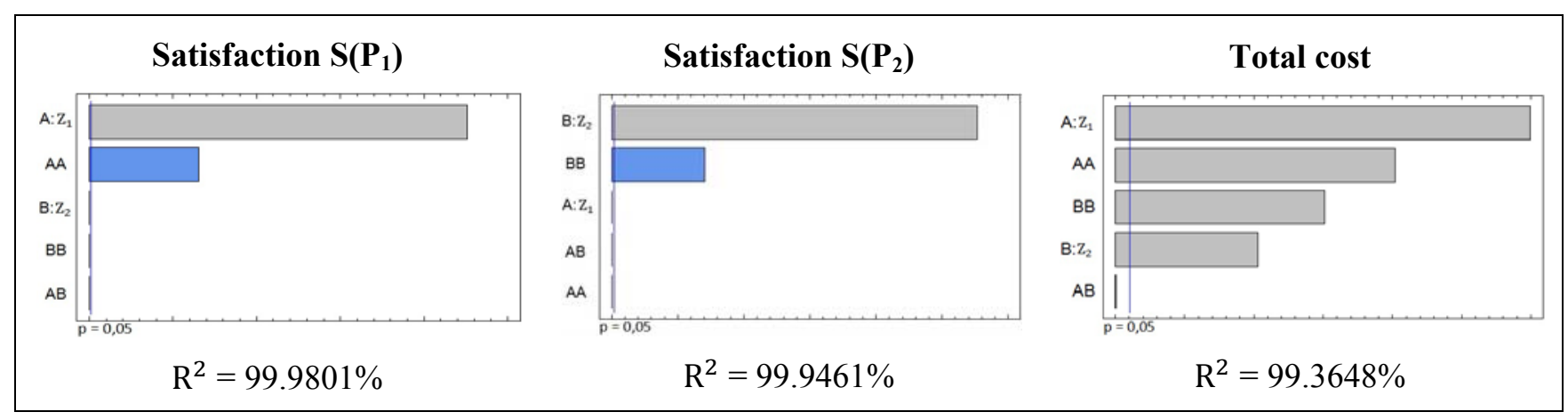

Figure 4. Pareto Chart for the dependent variables of the system

Furthermore, the adjusted correlation coefficients $\left(\mathrm{R}^{2}\right)$ show that more than $99 \%$ of the variability of the expected cost and customer satisfaction is explained by the response surface models (16), (17) and (18) [34]. An analysis of the residual normality and of the homogeneity of variance was also carried out to check the conformity of the model. The functions of the response surface of the dependent variables of the system are given by the following equations:

$$
\begin{aligned}
\operatorname{Cost}_{\mathrm{EXP} \_\mathrm{S}}= & 141,837-1.07706 \mathrm{Z}_{1}-4.09158 \mathrm{Z}_{2}+8.1819210^{-5} \mathrm{Z}_{1}^{2} \\
& +9.22334 * 10^{-5} \mathrm{Z}_{2}^{2} \\
\mathrm{~S}\left(\mathrm{P}_{1}\right)_{\mathrm{EXP} S \mathrm{~S}}= & 96.0052+4.30682 * 10^{-4} \mathrm{Z}_{1}-1.19771 * 10^{-8} \mathrm{Z}_{1}^{2}
\end{aligned}
$$




$$
\mathrm{S}\left(\mathrm{P}_{2}\right)_{\text {EXP_S }}=89.0623+6.99364 * 10^{-4} \mathrm{Z}_{2}-1.13255 * 10^{-8} \mathrm{Z}_{2}^{2}
$$

These three functions are used to compute the near optimal control policy that minimizes the cost (16) while respecting the customer satisfaction constraint given by equations (17) and (18). The near optimal control policy is defined by $\mathrm{Z}_{1}^{*}=12,389$ st and $\mathrm{Z}_{2}^{*}=24,544 \mathrm{st}$, which correspond to an average total cost of $270,244 \$$ day and service levels equal to $S\left(P_{1}\right)=S\left(P_{2}\right)=99.5 \%$.

In order to compare the above results generated by the proposed experimental approach (EXP_S) to those proposed by Dror's heuristic approach (HEU) $\left(Z_{1}=38,000\right.$ st and $Z_{2}=34,000$ st), 10 replications were performed with the simulation model developed. The proposal of Dror et al. [1] implies an average total cost of $311,837 \$$ day and service levels equal to $S\left(P_{1}\right)=99.99 \%$ and $\mathrm{S}\left(\mathrm{P}_{2}\right)=99.83 \%$. It is interesting to note that this proposal of Dror et al. [1] exceeds the customer service target $99.5 \%$ without taking into account any possible impact on the incurred costs. The results indicate that for a $99.5 \%$ customer satisfaction (the target level of service required), the experimental solution approach proposed in this article allows a total cost reduction of $15.39 \%$ versus the solution proposed by Dror et al. [1]. However, more analysis is needed in order to assess the quality of the results. To cross-check the validity of the model represented by equations (16)-(18), a Student's t-test is conducted [35]. The results confirm that the cost $(270,244 \$$ day) falls well within the $95 \%$ confidence interval $[270,058 ; 274,642]$ obtained using 100 replications of the simulation model.

\section{Integration of subcontracting as decision variable}

This section presents the general joint production/subcontracting control policy (EXP_G) presented in section 2.3 , and which considers the security stocks for the two products $\left(Z_{1}, Z_{2}\right)$, the rates of regular and urgent generic medication subcontracting $\left(\mathrm{U}_{\mathrm{st}}^{\mathrm{R}}, \mathrm{Q}_{\mathrm{st}}^{\mathrm{U}}(\mathrm{t})\right)$, as well as the threshold launch of urgent orders $\left(\mathrm{S}_{\mathrm{Q}}\right)$ as decision variables. In fact, Dror et al. [1] consider that the regular subcontracting rate is set in advance to $550 \mathrm{st} /$ day. However, taking into account the steady state availabilities of production facilities, the minimum rate of subcontracting required to satisfy the entire customer demand is $771 \mathrm{st} /$ day, as calculated by equation (19). 


$$
\mathrm{d}_{1}+\mathrm{d}_{2}-\sum_{\mathrm{j}=1}^{2}\left(\mathrm{U}_{\text {max }}^{2 \mathrm{j}} * \frac{\mathrm{MTBF}_{\mathrm{j}}}{\mathrm{MTBF}_{\mathrm{j}}+\mathrm{MTTR}_{\mathrm{j}}}\right)=771 \mathrm{st} / \text { day }
$$

Choosing a rate of a regular subcontracting which is equal to $550 \mathrm{st} /$ day effectively tends to increase the risk of stock-out. In case of failure, the only source for restoring the safety stock level by urgent subcontracting depends on relatively long and random delivery times. In addition, urgent orders are much more expensive than regular ones $\left(c_{s t}^{R}<c_{s t}^{u}\right)$. On the other hand, the system which deals with random perturbations of its production process is forced to protect itself by increasing the value of inventory capacities $\left(\mathrm{Z}_{1}\right.$ and $\left.\mathrm{Z}_{2}\right)$. This attitude generates high inventories and storage space costs.

In order to take into account all aspects influencing the performance of the production system, the general joint production/subcontracting control policy (EXP_G) considers the main decision variables, $Z_{1}, Z_{2}, U_{s t}^{R}, Q_{s t}^{U}(t)$ and $\beta$. The new variable $\beta$ is considered in order to ensure that $S_{Q} \leq Z_{2}$. So, $S_{Q}=\beta * Z_{2}$ and $0 \leq \beta \leq 1$. Because of the high number of control parameters included in the model, we proceed in two steps. First, we use a screening design to evaluate the importance of each of the independent variables [34]. This step does not determine the optimal control parameters, but measures the importance of these parameters and retains those which have a significant effect on the total incurred cost. Secondly, we determine the response surface functions of the dependent output variables of the system based on the significant factors, after which we determine the optimal solution. The adopted screening design is a full factorial design with 5 factors at 2 levels each $\left(2^{5}\right)$ and with 3 center points. Three replications are conducted for each combination of factors, and so a total of 105 simulations are performed. An analysis of variance (ANOVA) is then performed based on the results of the simulation using the statistical software, Statgraphics. The adjusted correlation coefficient $\left(\mathrm{R}^{2}\right)$ shows that the simulation model explains more than $93 \%$ of the variability of the expected total cost [34]. The analysis of variance also shows that the two factors $\left(Q_{s t}^{U}\right.$ and $\left.\beta\right)$, their double interactions, and their quadratic effects are not significant at a confidence level of $95 \%$ (see Figure 5). This is normal since urgent subcontracting depends on a non negligible random delivery time (see section 2.2) and since the urgent subcontracting cost is relatively higher than the regular one $\left(c_{s t}^{R}<c_{s t}^{u}\right)$. The response surface functions obtained using Statgraphics are given as follows: 


$$
\begin{aligned}
& \text { Cost }_{\text {EXP_G }}=639683.53-1.13 \mathrm{Z}_{1}-11.07 \mathrm{Z}_{2}-312.09 \mathrm{U}_{\mathrm{st}}^{\mathrm{R}}+6.55 .10^{-2} \mathrm{U}_{\mathrm{st}}^{\mathrm{R}^{2}} \\
& -3.20 \cdot 10^{-3} \mathrm{U}_{\mathrm{st}}^{\mathrm{R}} \mathrm{Z}_{1}+5.50 \cdot 10^{-3} \mathrm{U}_{\mathrm{st}}^{\mathrm{R}} \mathrm{Z}_{2}+1.04 \cdot 10^{-4} \mathrm{Z}_{1}^{2}-2.33 \cdot 10^{-3} \mathrm{Z}_{1} \mathrm{Z}_{2} \\
& +2.91 \cdot 10^{-10} \mathrm{Z}_{2}^{2} \\
& \mathrm{~S}\left(\mathrm{P}_{1}\right)_{\mathrm{EXP} \mathrm{P}_{-}}=96.01+6.09 \cdot 10^{-5} \mathrm{U}_{\mathrm{st}}^{\mathrm{R}}+4.07 \cdot 10^{-4} \mathrm{Z}_{1}+7.28 \cdot 10^{-6} \mathrm{Z}_{2}+6.38 \cdot 10^{-2} \beta \\
& +8.87 .10^{-5} \mathrm{Q}_{\mathrm{st}}^{\mathrm{U}}-1.75 \cdot 10^{-8} \mathrm{U}_{\mathrm{st}}^{\mathrm{R}}-1.10 \cdot 10^{-8} \mathrm{Z}_{1}^{2}-3.17 \cdot 10^{-10} \mathrm{Z}_{2}^{2} \\
& -1.06 \cdot 10^{-1} \beta^{2}-4.67 \cdot 10^{-8} Q_{s t}^{U^{2}} \\
& \mathrm{~S}\left(\mathrm{P}_{2}\right)_{\mathrm{EXP}_{-} \mathrm{G}}=52.33+1.68 \cdot 10^{-2} \mathrm{U}_{\mathrm{st}}^{\mathrm{R}}+7.65 \cdot 10^{-4} \mathrm{Z}_{1}+2.73 .10^{-3} \mathrm{Z}_{2}+6.68 \beta \\
& +9.45 \cdot 10^{-3} \mathrm{Q}_{\mathrm{st}}^{\mathrm{U}}-1.15 \cdot 10^{-6} \mathrm{U}_{\mathrm{st}}^{\mathrm{R}}-5.94 \cdot 10^{-7} \mathrm{U}_{\mathrm{st}}^{\mathrm{R}} \mathrm{Z}_{2}-3.32 \cdot 10^{-8} \mathrm{Z}_{1}^{2} \\
& -5.56 \cdot 10^{-8} \mathrm{Z}_{2}^{2}-11.43 \beta^{2}-4.97 \cdot 10^{-6} \mathrm{Q}_{\mathrm{st}}^{\mathrm{U}}
\end{aligned}
$$

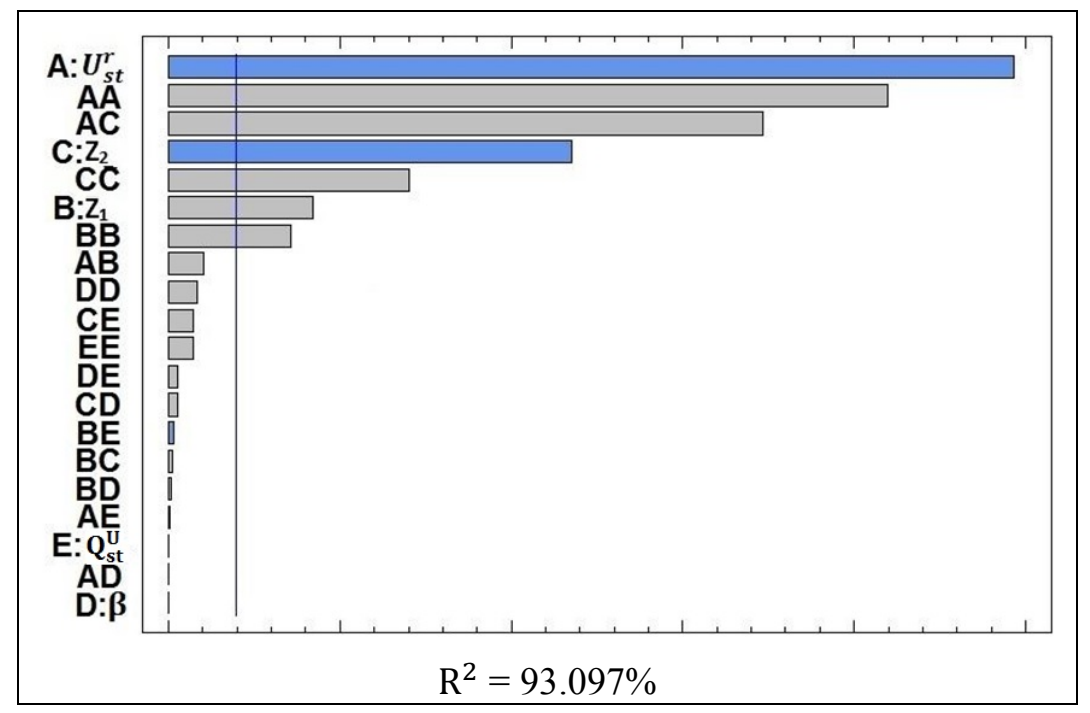

Figure 5. Pareto Chart for the total cost parameter of the EXP_G

To further explore the contribution of subcontracting, two new joint production/subcontracting control policies will be considered, and thereby the subcontracting will be either urgent or regular. Therefore, in addition to $Z_{1}$ and $Z_{2}$, one or more decision variables which will represent the subcontracting activity $\left(\mathrm{U}_{\mathrm{st}}^{\mathrm{R}}, \mathrm{Q}_{\mathrm{st}}^{\mathrm{U}}(\mathrm{t})\right.$ and $\left.\mathrm{S}_{\mathrm{Q}}\right)$ are also taken into account:

\subsection{Joint production / urgent subcontracting control policy (EXP_Urg)}

This policy uses only the urgent subcontracting to remedy the lack of production capacity of both facilities. When the level of product inventory $\mathrm{P}_{2}$ decreases and then reaches the threshold $\mathrm{S}_{\mathrm{Q}}$ 
$\left(\mathrm{x}_{2}=\mathrm{S}_{\mathrm{Q}}\right)$, a subcontracting order is issued in order to be delivered after a random transportation delay (TD). The equation (11) becomes as follows:

$$
\mathrm{U}_{\mathrm{st}}(\mathrm{t}): \begin{cases}\mathrm{Q}_{\mathrm{st}}^{\mathrm{U}}(\mathrm{t}+\mathrm{TD}) & \text { if } \mathrm{x}_{2}=\mathrm{S}_{\mathrm{Q}} \\ 0 & \text { otherwise }\end{cases}
$$

With,

$$
\mathrm{Q}_{\mathrm{st}}^{\mathrm{U}}(\mathrm{t}) \geq 0 ; \mathrm{Q}_{\mathrm{st}}^{\mathrm{U}}(\mathrm{t})+\left[\left(1-\frac{\mathrm{d}_{1}}{\sum_{\mathrm{j}=1}^{\mathrm{m}} \mathrm{U}_{\text {max }}^{1 \mathrm{j}}}\right) *\left(\sum_{\mathrm{j}=1}^{2}\left(\mathrm{U}_{\max }^{2 \mathrm{j}} * \frac{\mathrm{MTBF}_{\mathrm{j}}}{\operatorname{MTBF}_{\mathrm{j}}+\mathrm{MTTR}_{\mathrm{j}}}\right)\right)\right] \geq \mathrm{d}_{2}, \forall \mathrm{j} \in \mathrm{J}
$$

The order quantity $\left(Q_{\mathrm{st}}^{\mathrm{U}}\right)$ is a decision variable to be optimized. It is interesting to note that the non consideration of the regular subcontracting implies that the inventory level $\left(\mathrm{x}_{2}\right)$ cannot be stabilized at its threshold $Z_{2}^{*}$ (see Figure 3 - (1)) since the production capacity dedicated to produce $\mathrm{P}_{2}$ is less than the demand rate of $\mathrm{P}_{2}$. Therefore, the parameter $\mathrm{Z}_{2}$ is omitted from the optimisation model and the storage space cost is calculated according to the higher value recorded by the $\mathrm{x}_{2}$.

In this section, we adopt the same approach considered in section 6, except that the objective is to determine the optimal value of three control parameters of the EXP_Urg $\left(Z_{1}, \beta\right.$ and $\left.Q_{s t}^{U}(t)\right)$ which minimize the incurred total cost (6) according to the required level of service (12). Recall that $\beta$ is considered in order to ensure that $S_{Q} \leq Z_{2}$, with $0 \leq \beta \leq 1$ and $S_{Q}=\beta * Z_{2}$. Considering the same base case numerical data (see section 6), a full $3^{3}$ experimental design is also used, and five replications performed for each combination of factors. Therefore, a total of $135\left(3^{3} * 5\right)$ simulations are performed. According to the resulting adjusted correlation coefficients $\left(\mathrm{R}^{2}\right)$, over $95 \%$ of the system variability is explained by the model $\left(\mathrm{R}_{\text {Cost }}^{2}=95.38 \%, \mathrm{R}_{\mathrm{S}\left(\mathrm{P}_{1}\right)}^{2}=99.97 \%\right.$ and $\left.\mathrm{R}_{\mathrm{S}\left(\mathrm{P}_{2}\right)}^{2}=99.56 \%\right)$. The response surface functions are given as follows:

$$
\begin{aligned}
\text { Cost }_{\text {EXP_Urg }}= & 463279-1.07 \mathrm{Z}_{1}-1.06 \beta-5.86 \mathrm{Q}_{\mathrm{st}}^{\mathrm{U}}+8.82 \cdot 10^{-5} \mathrm{Z}_{1}^{2}-6.11 \cdot 10^{-10} \mathrm{Z}_{1} \mathrm{Q}_{\mathrm{st}}^{\mathrm{U}} \\
& +2.98 \cdot 10^{-5} \beta^{2}+3.26 \cdot 10^{-6} \beta \mathrm{Q}_{\mathrm{st}}^{\mathrm{U}}-4.94 \cdot 10^{-5} \mathrm{Q}_{\mathrm{st}}^{\mathrm{U}^{2}} \\
\mathrm{~S}_{\left(\mathrm{P}_{1}\right)_{\text {EXP_Urg }}=} & 96.22+4.14 \cdot 10^{-4} \mathrm{Z}_{1}-1.47 \cdot 10^{-6} \mathrm{Q}_{\mathrm{st}}^{\mathrm{U}}-1.19 \cdot 10^{-8} \mathrm{Z}_{1}^{2} \\
\mathrm{~S}\left(\mathrm{P}_{2}\right)_{\text {EXP_Urg }_{-}=} & 87.24+3.56 \cdot 10^{-4} \beta+2.24 \cdot 10^{-4} \mathrm{Q}_{\mathrm{st}}^{\mathrm{U}}-4.24 .10^{-9} \beta^{2}-1.40 .10^{-9} \beta \mathrm{Q}_{\mathrm{st}}^{\mathrm{U}} \\
& -1.43 \cdot 10^{-9} \mathrm{Q}_{\mathrm{st}}^{\mathrm{U}}
\end{aligned}
$$




\subsection{Joint production / regular subcontracting control policy (EXP_Reg)}

This policy does not use the urgent subcontracting. It merely considers the two manufacturing facilities and the regular subcontracting in order to ensure the satisfaction of the demand. As a

result, the urgent subcontracting quantity to be ordered $\left(\mathrm{Q}_{s t}^{\mathrm{U}}(\mathrm{t})\right)$ and the threshold for launching urgent orders $\left(\mathrm{S}_{\mathrm{Q}}\right)$ are no longer considered in the joint production / regular subcontracting control policy (EXP_Reg). Note that equation (19) becomes $U_{\mathrm{st}}^{\mathrm{R}} \geq 771 \mathrm{st} /$ day and equation (11) becomes as follows: $\mathrm{U}_{\mathrm{st}}(\mathrm{t})=\mathrm{U}_{\text {st }}^{\mathrm{R}}$.

In order to determine the optimal value of three control parameters of the EXP_Reg $\left(Z_{1}, Z_{2}\right.$ and $\mathrm{U}_{\mathrm{st}}^{\mathrm{R}}$ ), we adopt the same approach and the same tools considered in section 6.2. With more than $96 \%$ of the system variability which is explained by the model $\left(\mathrm{R}_{\text {Cost }}^{2}=96.44 \%\right.$, $R_{S\left(P_{1}\right)}^{2}=99.96 \%$ and $\left.R_{S\left(P_{2}\right)}^{2}=99.61 \%\right)$ ). The response surface functions of the EXP_Reg are given as follows:

$$
\begin{aligned}
\text { Cost }_{\text {EXP_Reg }}= & 474072-179.73 \mathrm{U}_{\mathrm{st}}^{\mathrm{R}}-1.13 \mathrm{Z}_{1}-10.79 \mathrm{Z}_{2}+3.69 \cdot 10^{-2} \mathrm{U}_{\mathrm{st}}^{\mathrm{R}} \\
& -3.20 \cdot 10^{-10} \mathrm{U}_{\mathrm{st}}^{\mathrm{R}} \mathrm{Z}_{1}+4.27 \cdot 10^{-3} \mathrm{U}_{\mathrm{st}}^{\mathrm{R}} \mathrm{Z}_{2}+1.04 \cdot 10^{-4} \mathrm{Z}_{1}^{2}-2.33 \cdot 10^{-1} \mathrm{Z}_{1} \mathrm{Z}_{2} \\
& +1.40 \cdot 10^{-4} \mathrm{Z}_{2}^{2} \\
\mathrm{~S}\left(\mathrm{P}_{1}\right)_{\text {EXP_Reg }}= & 96.12+4.24 * 10^{-4} \mathrm{Z}_{1}-1.22 .10^{-8} \mathrm{Z}_{1}^{2} \\
\mathrm{~S}\left(\mathrm{P}_{2}\right)_{\text {EXP_Reg }}= & 61.74+2.29 .10^{-2} \mathrm{U}_{\mathrm{st}}^{\mathrm{R}}+2.03 \cdot 10^{-3} \mathrm{Z}_{2}-3.45 \cdot 10^{-6} \mathrm{U}_{\mathrm{st}}^{\mathrm{R}}{ }^{2} \\
& -5.57 \cdot 10^{-7} \mathrm{U}_{\mathrm{st}}^{\mathrm{R}} \mathrm{Z}_{2}-3.47 .10^{-8} \mathrm{Z}_{2}^{2}
\end{aligned}
$$

\subsection{Comparison of the three control policies considering the subcontracting as a decision variable}

The response surface functions (20) - (28) of the three control policies EXP_Urg, EXP_Reg and EXP_G, are used in order to determine the optimal parameters which minimize the total cost (6) incurred while respecting the customer satisfaction constraint. Table 4 presents the optimization results, provided that the customer service level is greater than or equal to $99.5 \%$. 
Table 4. Optimization results for a service level higher than or equal to $99.5 \%$

\begin{tabular}{|c|c|c|c|c|c|c|}
\hline Policy & $\mathbf{Z}_{\mathbf{1}}^{*}(\mathbf{s t})$ & $\mathbf{Z}_{\mathbf{2}}^{*}$ (st) & $\mathbf{U}_{\text {st }}^{\mathbf{R}^{*}}$ (st/day) & $\mathbf{S}_{\mathbf{Q}}(\mathbf{s t})$ & $\mathbf{Q}_{\mathbf{s t}}^{\mathbf{U}^{*}}$ (st) & Cost (\$/day) \\
\hline EXP_Urg & 12,598 & - & - & 21,894 & 59,602 & 285,741 \\
\hline EXP_Reg & 12,365 & 10,922 & 1,924 & - & - & 255,604 \\
\hline EXP_G & 12,463 & 20,425 & 1,604 & 5,914 & 978 & 253,449 \\
\hline
\end{tabular}

To study the advantage in terms of costs of one policy over another, a Student's t-test is conducted using the cost difference between the three considered control policies [35]. Table 5 presents the $95 \%$ confidence intervals of the cost differences $C_{\text {EXP_Urg }}^{*}-C_{E X P_{-} R e g}^{*}, C_{E X P_{-} U r g}^{*}-C_{E X P_{-} G}^{*}$ and $\mathrm{C}_{\mathrm{EXP} \_ \text {Reg }}^{*}-\mathrm{C}_{\mathrm{EXP}_{\mathrm{G}}}^{*}$, obtained using 20 replications of the simulation model. It shows that the lower and the upper bounds of the confidence intervals of the cost differences $\mathrm{C}_{\mathrm{EXP} \_ \text {Urg }}^{*}-\mathrm{C}_{\mathrm{EXP} \_ \text {Reg }}^{*}$ as well as $\mathrm{C}_{\text {EXP_Urg }}^{*}-\mathrm{C}_{\text {EXP_G }}^{*}$ are positive. These results can be interpreted as EXP_Reg and EXP_G being better than EXP_Urg, in the sense that the latter generates higher total cost than the other control policies. Table 5 also shows that the confidence interval for $\mathrm{C}_{\mathrm{EXP}}^{*} \mathrm{Reg}_{-}-\mathrm{C}_{\mathrm{EXP} \_\mathrm{G}}^{*}$ contains zero. This means that there is no statistical evidence that one control policy is better than the other in terms of cost [35].

Table 5. Cost difference confidence interval (95\%)

\begin{tabular}{|c|c|c|c|}
\hline Policy & $\mathrm{C}_{\text {EXP_Urg }}^{*}-\mathrm{C}_{\text {EXP_Reg }}^{*}$ & $\mathrm{C}_{\text {EXP_Urg }}^{*}-\mathrm{C}_{\text {EXP_G }}^{*}$ & $\mathrm{C}_{\text {EXP_Reg }}^{*}-\mathrm{C}_{\text {EXP_G }}^{*}$ \\
\hline Lower bound & 29,772 & 29,580 & -197 \\
\hline Upper bound & 29,991 & 29,982 & 99 \\
\hline
\end{tabular}

Further analyses were conducted in order to study the influence of the urgent subcontracting cost $\left(c_{s t}^{u}\right)$ on the total cost of the considered joint control policies. In this sense, Figure 6.a shows that the EXP_G becomes more advantageous in term of costs than the EXP_Reg when $c_{\text {st }}^{\mathrm{u}}$ is less than 76 (both upper and lower bounds of the confidence intervals of the cost differences $\mathrm{C}_{\mathrm{EXP} \_ \text {Reg }}^{*}-$ $\mathrm{C}_{\text {EXP_G }}^{*}$ are positive). This value represents only $26.67 \%$ more than of the value of the regular subcontracting cost $\left(c_{s t}^{R}\right)$; this is unlikely, since $c_{s t}^{u}$ should be much more expensive. In the same context, the value of the average total cost of EXP_Urg falls below that of EXP_Reg only when $c_{\mathrm{st}}^{\mathrm{u}}$ is less than 54 (see Figure 6.b), which is less than the value of the regular subcontracting cost $\left(c_{s t}^{R}=60\right)$. These situations are not possible in several industries such as the pharmaceutical one. The contract agreement with regular subcontractor allows him to deliver goods that cost less than 
those obtained with urgent orders from different subcontractors. Indeed, subcontractors often aim to maximize their profit from occasional orders. In addition, regular subcontracting can be very useful to reduce the adverse effects of random transportation delays, to ensure an efficient control, an ease of management as well as an effective traceability of the subcontracted products and to demand the highest standards of quality during contract negotiations that should cover all aspects related to the management of products and services. For these reasons we chose the EXP_Reg as the best joint production / subcontracting control policy for the considered manufacturing system. This control policy will be studied in depth and compared to the solution recommended by Dror et al. [1] and to the control policy presented in Section 6 (EXP_S).

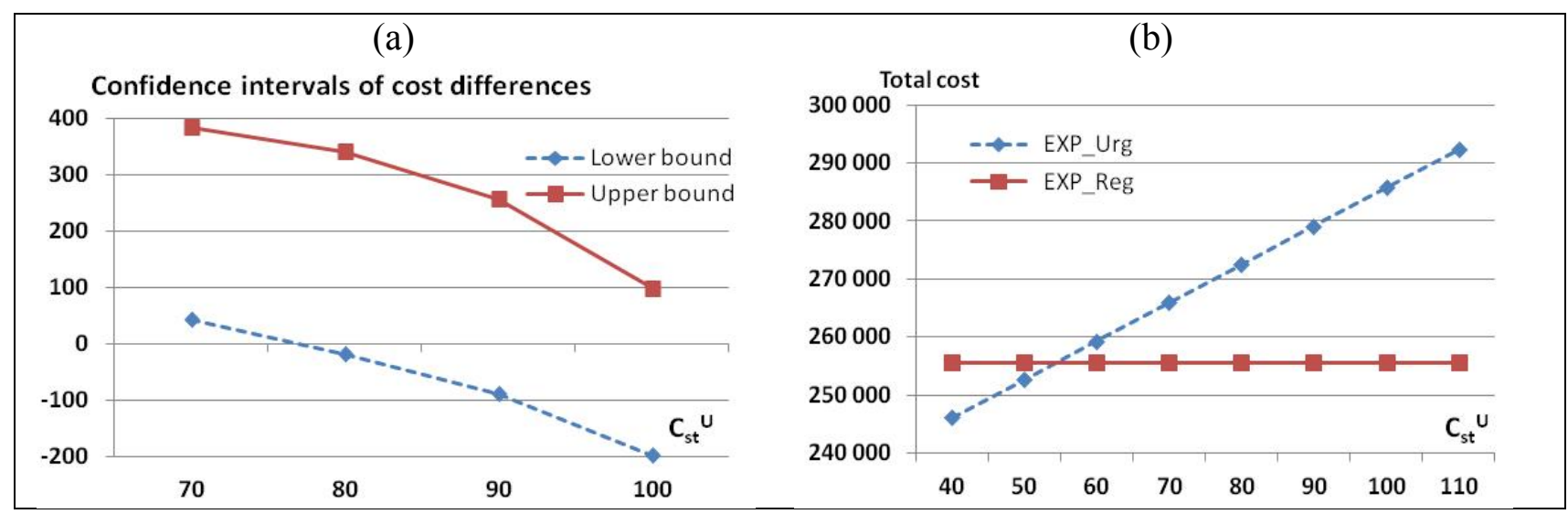

Figure 6. Comparisons between EXP_G and EXP_Reg (a) and between EXP_Urg and EXP_Reg (b) according to $\mathrm{c}_{\mathrm{st}}^{\mathrm{u}}$

\section{Analysis of the joint production / regular subcontracting control policy}

Table 6 presents the solution proposed by Dror et al. [1] (HEU) as well as results of the optimization of both control policies: EXP_S and EXP_Reg, provided that the customer service level is greater than or equal to $99.5 \%$.

Table 6. Solutions of the three models selected for a service level higher than or equal to $99.5 \%$

\begin{tabular}{|c|c|c|c|c|c|}
\hline Solving approach & Policy & $\mathbf{Z}_{\mathbf{1}}^{*}(\mathbf{s t})$ & $\mathbf{Z}_{\mathbf{2}}^{*}(\mathbf{s t})$ & $\mathbf{U}_{\mathbf{s t}}^{\mathbf{R}^{*}}$ (st/day) & Cost (\$/day) \\
\hline Heuristic (Dror policy) & HEU & 38,000 & 34,000 & 550 & 311,837 \\
\hline Experimental (Dror policy) & EXP_S & 12,389 & 24,544 & 550 & 270,244 \\
\hline Experimental (Proposed policy) & EXP_Reg & 12,365 & 10,922 & 1,924 & 255,604 \\
\hline
\end{tabular}


The results presented in Table 6 show that the joint production/regular subcontracting control policy (EXP_Reg) provides a significant economic gain when combined with the experimental approach. This gain reaches a value of $18 \%$ when compared to the solution proposed by Dror et al. [1].

\subsection{Effect of the customer service level on the control parameters}

By using equation (26) with constraints (27) and (28), we have determined the behaviour of the optimal parameters of the control policy as well as the associated cost, according to changes in customer satisfaction (Figures 7 - 10). Figure 7 shows variations in the control parameter values based on the customer satisfaction level.

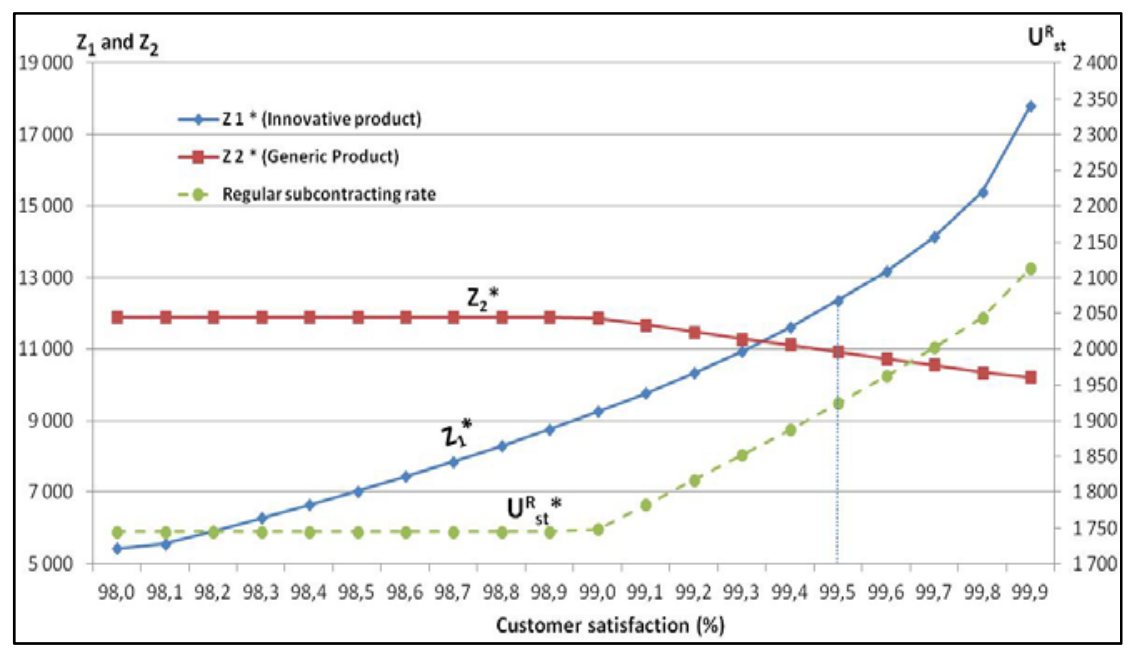

Figure 7. Variation of control parameters of the EXP_Reg based on customer satisfaction

Figure 7 shows that the parameter $\mathrm{Z}_{1}^{*}$ increases according to customer satisfaction in order to reduce stock-outs of the product $\mathrm{P}_{1}$. Unlike product $\mathrm{P}_{1}$, the required growth in customer service level of $\mathrm{P}_{2}$ implies an increase of the value of the regular subcontracting rate $\left(\mathrm{U}_{\mathrm{st}}^{\mathrm{R} *}\right)$ rather than that of $\mathrm{Z}_{2}^{*}$. Indeed, the increase of $\mathrm{U}_{\mathrm{st}}^{\mathrm{R}}{ }^{*}$ in this case becomes more economical than that of $\mathrm{Z}_{2}^{*}$, which generates very high costs especially those associated with storage. We should recall that the storage costs penalize the space in the form of an average cost per unit of time for each interval depending on the value of $Z_{2}$ (section 2.2). The additional quantities of the regular subcontracting are also used to reduce the impact of the system's failure as well as to accelerate 
the restoration of the inventory of the product $P_{2}$. This choice, which consists in increasing $U_{\text {st }}^{R *}$ implies a significant reduction of the value of $Z_{2}$ for the total cost incurred (Figure 7). We note that the range in which the control parameters are constant corresponds to the situations where the values of $\mathrm{Z}_{1}^{*}, \mathrm{Z}_{2}^{*}$ and $\mathrm{U}_{\mathrm{st}}^{\mathrm{R}}{ }^{*}$ generate a higher level of service when compared to that required by the customer satisfaction constraint. Indeed, when the customer satisfaction constraint is deleted, the calculated values of $\mathrm{Z}_{1}^{*}$ and $\mathrm{Z}_{2}^{*}$, which minimize the total incurred cost, generate a service level of $98.07 \%$ and $98.99 \%$ for the two product types $\mathrm{P}_{1}$ and $\mathrm{P}_{2}$, respectively.

From Figure 8, we note that the average total cost grows exponentially in terms of customer satisfaction without ever exceeding that proposed by Dror et al. [1]. This growth is explained by the increase of the control parameters $\mathrm{Z}_{1}^{*}$ and $\mathrm{U}_{\mathrm{st}}^{\mathrm{R}}$, and consequently, by the growth of the inventory costs and storage space for the product $\mathrm{P}_{1}$ and of the cost of regular subcontracting for the product $\mathrm{P}_{2}$ (Figure 7).

To confirm the robustness of the solution generated by the model, we proceed with the same analysis, but adopting the following constraint: $U_{\mathrm{st}}^{\mathrm{R}} \leq 1745$ (Figure 7). This condition causes the system to increase the value of $\mathrm{Z}_{2}^{*}$ in order to achieve a higher service level $\left(\mathrm{S}\left(\mathrm{P}_{1}\right) \& \mathrm{~S}\left(\mathrm{P}_{2}\right)>98 \%\right)$. In fact, $\mathrm{U}_{\mathrm{st}}^{\mathrm{R}}$ must remain less than or equal to 1745 (optimal value obtained for $\left.\mathrm{S}\left(\mathrm{P}_{1}\right)=\mathrm{S}\left(\mathrm{P}_{2}\right)=98 \%\right)$. This specific policy is denoted EXP_Reg2, and Figure 9 summarizes the results.

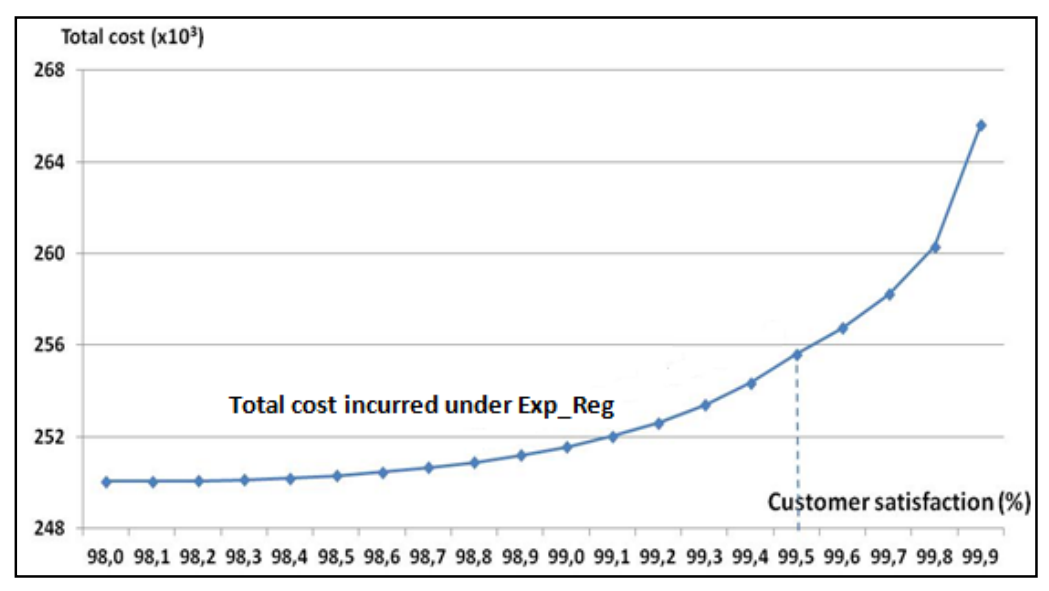

Figure 8. Variation of the average optimal total cost in terms of customer satisfaction (EXP_Reg) 


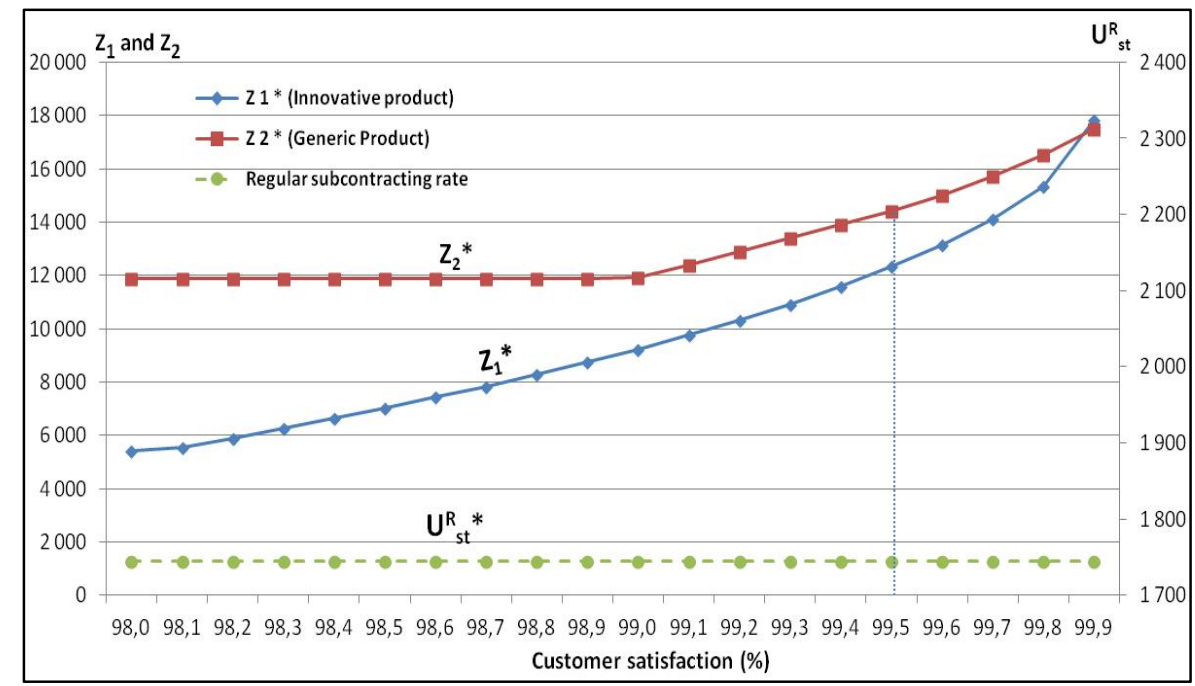

Figure 9. Variation of the optimal parameters of the model EXP_Reg2 based on customer satisfaction when $\mathrm{U}_{\mathrm{st}}^{\mathrm{R}}(\mathrm{t}) \leq 1745$

Figure 10 shows the difference between the total costs of the two policies EXP_Reg and EXP_Reg2, depending on the client satisfaction level. It demonstrates the advantage of increasing the value of the regular subcontracting rate $\left(\mathrm{U}_{\mathrm{st}}^{\mathrm{R}}\right)$ rather than that of $\mathrm{Z}_{2}^{*}$ in order to achieve a higher service level. This difference in total cost is expressed by: D.C. $\left(U_{\text {st }}^{R}\right)=$ C.T.EXP_Reg2 - C.T.EXP_Reg $\cdot$

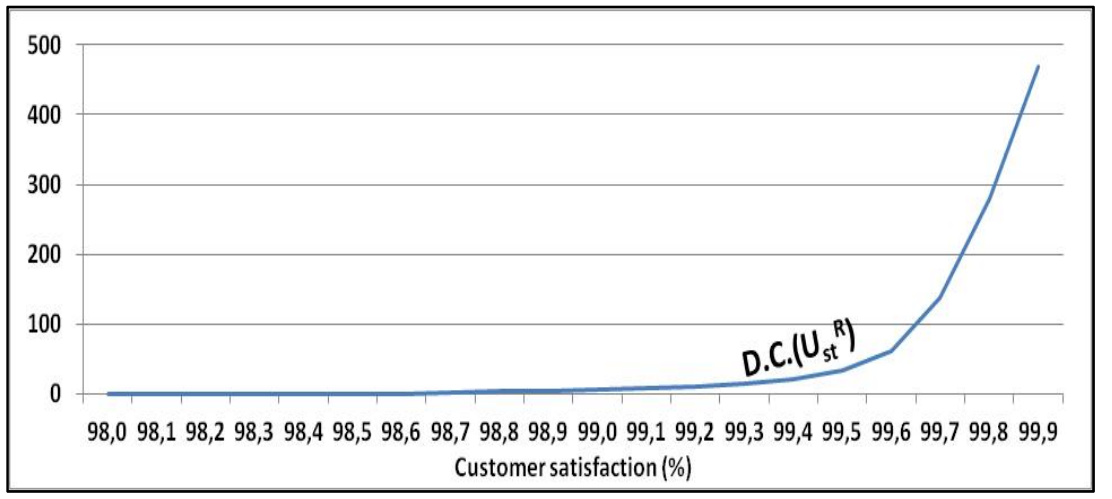

Figure 10. Difference in the total cost between the policies EXP_Reg and EXP_Reg2, depending on customer satisfaction 


\subsection{Effect of shortage cost $\left(c_{2}^{-}\right)$on control parameters}

From Table 6, we note that the joint production / regular subcontracting control policy (EXP_Reg) allowed the value of $\mathrm{U}_{\mathrm{st}}^{\mathrm{R}}$ to increase and the critical threshold $\mathrm{Z}_{2}^{*}$ of the product $\mathrm{P}_{2}$ to drop significantly. The threshold $\mathrm{Z}_{1}$ of the innovative product $\mathrm{P}_{1}$ has decreased slightly since the subcontracting concerns only the generic product $\mathrm{P}_{2}$. Given the value of the minimum subcontracting amount $\left(\mathrm{U}_{\mathrm{st}}^{\mathrm{R}} \geq 771 \mathrm{st} / \mathrm{day}\right)$, we note that the optimal value of the subcontracting rate is more than twice as high as its minimal rate, which affects the global utilization rate of the two facilities (Table 7). In fact, $25.78 \%$ of the facilities' capacity is not in use, with this value not including maintenance idle times. This unexpected phenomenon is due to the reaction of the model, which must simultaneously satisfy the constraint of the feasibility of the system (5) on the one hand, and protect itself against the fluctuations of random events (failure occurrences, repair action durations, etc.), on the other. In addition, and due to high product shortage costs and the imposed customer service level $(99.5 \%)$, the model seeks to avoid stock-outs. Consequently, it minimizes the impact of the stock-out on both the cost and the customer satisfaction by increasing the value of $\mathrm{U}_{\mathrm{st}}^{\mathrm{R}}$ which reduces the use of the manufacturing facilities.

Figures 11 and 12 represent the behavior of the system when varying the shortage cost of the product $\mathrm{P}_{2}$ and the customer satisfaction, respectively. They show that the growth of $\mathrm{c}_{2}^{-}$for a customer satisfaction of $99.5 \%$, does not affect the value of $\mathrm{Z}_{1}^{*}$ but increases the storage capacity of the product $\mathrm{P}_{2}\left(\mathrm{Z}_{2}\right.$ increases) so as to avoid the additional shortage costs (Figure 11). This behavior, observed by Gharbi et al. [21, 24] and Lavoie et al. [28], reduces the risk of stock-outs and increases the customer satisfaction level. As a result, the system decides to decrease the value of $\mathrm{U}_{\mathrm{st}}^{\mathrm{R}^{*}}$ (Figure 12) in order to reduce the cost of regular subcontracting while maintaining a minimum service level of $99.5 \%$. In addition, Figure 12 shows that the decrease of $\mathrm{U}_{\mathrm{st}}^{\mathrm{R}^{*}}$ increases the percentage of capacity utilization of the two facilities. Indeed, $\mathrm{U}_{\mathrm{st}}^{\mathrm{R}^{*}}$ is not only used to accelerate the restoration of the inventory level of the product $\mathrm{P}_{2}$, but also to satisfy an important part of customer demand $\mathrm{d}_{2}$. Likewise, when the value of $\mathrm{U}_{\mathrm{st}}^{\mathrm{R}}{ }^{*}$ decreases, the capacity used to produce $\mathrm{P}_{2}$ increases in order to meet the overall demand $\mathrm{d}_{2}$. 


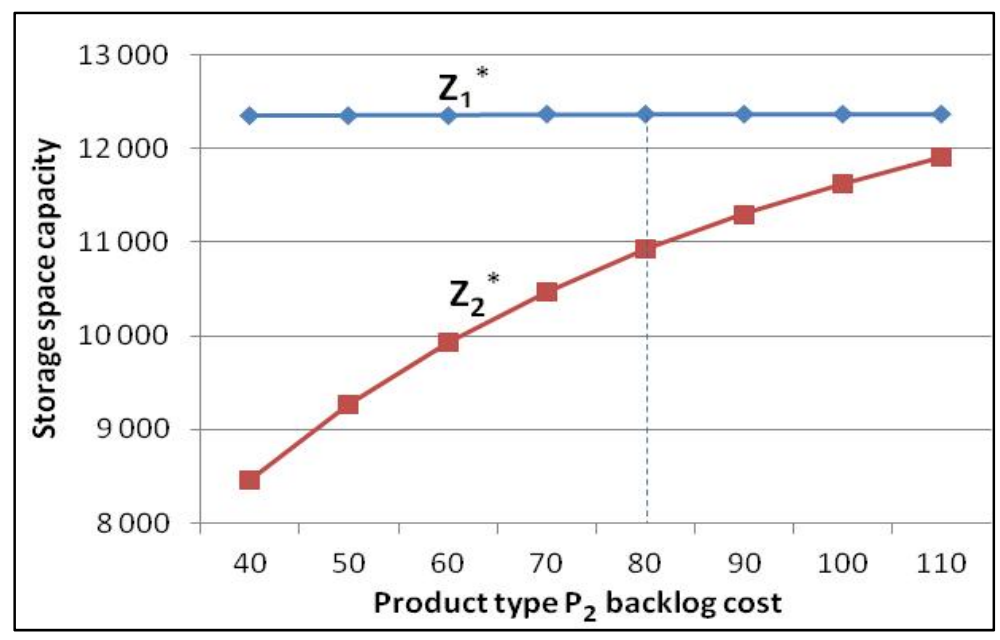

Figure 11. Variation of the optimal value of the thresholds according to $c_{2}^{-}$for a $99.5 \%$ service level

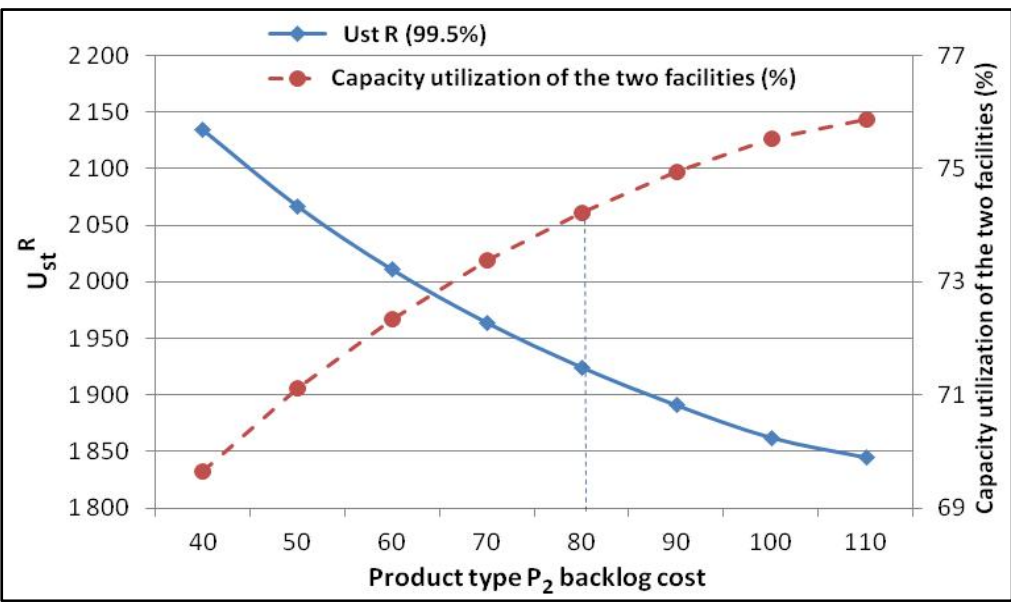

Figure 12. Variation of the regular subcontracting rate and the percentage of capacity utilization (C.U.) of facilities based on $c_{2}^{-}$for a $99.5 \%$ service level

\subsection{Sensitivity Analysis}

A sensitivity analysis based on a series of numerical examples was carried out in order to confirm the robustness of the solution approach and the effectiveness of the proposed control policy. Indeed, we studied the effect of different combinations of cost parameters on the control parameters of the model and on the total cost incurred. Thus, the improvements are confirmed in different contexts (Table 7). These configurations are also evaluated with respect to the basic model in order to study the behavior of the system. 
- Variation of $\mathrm{c}_{1}^{+}$(cases 1 and 2)

The variation of $\mathrm{c}_{1}^{+}$has no influence on the optimal value of the control parameter $\mathrm{Z}_{1}^{*}$. In fact, the subcontracting takes only into consideration the product $\mathrm{P}_{2}$.

- Variation of $\mathrm{c}_{2}^{+}$(cases 3 and 4 )

When $\mathrm{c}_{2}^{+}$increases, the storage space capacity dedicated to the product $\mathrm{P}_{2}\left(\mathrm{Z}_{2}^{*}\right)$ decreases in order to avoid additional inventory costs. This reduction implies a greater risk of stock-out and a lower level of customer satisfaction, hence the increase of the value of $\mathrm{U}_{\mathrm{st}}^{\mathrm{R}^{*}}$. The growth of the total cost incurred was primarily due to the growth of the inventory costs as well as the storage and the subcontracting costs of the product $\mathrm{P}_{2}$. The opposite occurs when $\mathrm{c}_{2}^{+}$decreases.

- Variation of $\mathrm{c}^{\mathrm{e}}$ (cases 5 and 6 )

This variation affects the control policy in the same way as the variation of $\mathrm{c}_{2}^{+}$.

- Variation of $c_{1}^{-}$(cases 7 and 8 )

This variation does not affect the value of the control parameters of the system. This is because the subcontracting only takes into consideration the product $\mathrm{P}_{2}$.

- Variation of $\mathrm{c}_{2}^{-}$(cases 9 and 10$)$

The variation of $c_{2}^{-}$has an inverse effect on the control parameters, compared with the variation of the inventory cost $\left(\mathrm{c}_{2}^{+}\right)$. Indeed, when $\mathrm{c}_{2}^{-}$increases, $\mathrm{Z}_{2}^{*}$ increases as well in order to avoid additional shortage costs. This increase implies a growth in the value of the customer satisfaction level. Accordingly, the system decreases the value of $\mathrm{U}_{\mathrm{st}}^{\mathrm{R}}{ }^{*}$ in order to reduce the cost of regular subcontracting while maintaining a minimum service level of $99.5 \%$. The increase in the total cost incurred is mainly due to the shortage cost. The opposite occurs when $c_{2}^{-}$decreases.

- Variation of $\mathrm{c}_{1}^{\mathrm{p}}$ (cases 11 and 12 )

This variation has no influence on the optimal value of the control parameters $\left(\mathrm{Z}_{1}^{*}, \mathrm{Z}_{2}^{*}\right.$ et $\left.\mathrm{U}_{\mathrm{st}}^{\mathrm{R}}\right)$. This is explained by the priority given to the product $\mathrm{P}_{1}$ which is manufactured solely by the company. In order to satisfy the customer demand $d_{1}$, this type of product is manufactured internally, whatever its production costs. 
- Variation of $\mathrm{c}_{2}^{\mathrm{p}}$ (cases 13 and 14$)$

The variation in the production $\operatorname{cost} c_{2}^{\mathrm{p}}$ affects the rate of the regular subcontracting $\left(\mathrm{U}_{\mathrm{st}}^{\mathrm{R}}{ }^{*}\right)$ and the threshold value $\left(\mathrm{Z}_{2}^{*}\right)$ of the product $\left(\mathrm{P}_{2}\right)$. This phenomenon is justified by the fact that the model EXP_Reg has allowed a percentage of the production capacity of the product $\mathrm{P}_{2}$ to be replaced by subcontracting. Thus, the increase in $c_{2}^{p}$ increases the value of $U_{s t}^{R}$ in order to reduce the manufactured quantity of product; which accounts for the decrease of $Z_{2}^{*}$. The opposite occurs when reducing $\mathrm{c}_{2}^{\mathrm{p}}$.

- Variation of $c_{\mathrm{st}}^{\mathrm{R}}$ (cases 15 and 16 )

When $c_{\mathrm{st}}^{\mathrm{R}}$ increases, $\mathrm{U}_{\mathrm{st}}^{\mathrm{R}}$ decreases in order to avoid additional regular subcontracting costs. This reduction of the $\mathrm{U}_{\mathrm{st}}{ }^{*}$ has the effect of increasing the risk of stock-out. Therefore, the system increases the value of $Z_{2}^{*}$ to reduce the shortage cost and to keep a service level of $99.5 \%$. The increase of the total cost is mainly due to the growth in the cost of regular subcontracting. The opposite occurs when $\mathrm{c}_{\mathrm{st}}^{\mathrm{R}}$ decreases.

The data in Table 7 shows that the increase (decrease) of regular subcontracting costs increases (reduces) the utilization capacity percentage of the two facilities. As already mentioned in section 8.1, this is due to the fact that regular subcontracting is used to satisfy the customer demand $\mathrm{d}_{2}$ and to restore the inventory level of the product $\mathrm{P}_{2}$. It should be noted that only the production rate of the product $\mathrm{P}_{2}$ affects the variation in the percentage of utilization capacity of the two facilities. 


\begin{tabular}{|c|c|c|c|c|c|c|c|c|c|c|c|c|c|c|c|c|c|c|c|}
\hline \multirow{2}{*}{ Cases } & \multicolumn{2}{|c|}{$\mathbf{c}_{\mathrm{i}}^{+}$} & \multirow{2}{*}{$\mathbf{c}^{\mathbf{e}}$} & \multicolumn{2}{|c|}{$c_{i}^{-}$} & \multicolumn{2}{|c|}{$c_{i}^{p}$} & \multirow{2}{*}{$\mathbf{c}_{\mathrm{st}}^{\mathrm{R}}$} & \multirow{2}{*}{$c_{s t}^{u}$} & \multirow{2}{*}{$\begin{array}{c}\text { Capacity } \\
\text { utilization } \\
\text { of the } 2 \\
\text { facilities (\%) }\end{array}$} & \multirow{2}{*}{$\begin{array}{c}\mathbf{U}_{\mathrm{st}}^{\mathrm{R}^{*}} \\
\text { (st/day) }\end{array}$} & \multirow{2}{*}{$\begin{array}{l}\mathrm{Z}_{1}^{*} \\
\text { (st) }\end{array}$} & \multirow{2}{*}{$\begin{array}{l}\mathrm{Z}_{2}^{*} \\
\text { (st) }\end{array}$} & \multicolumn{3}{|c|}{ Total cost (\$/day) } & \multicolumn{2}{|c|}{$\begin{array}{c}\text { Improvement } \\
\text { cost }(\%)\end{array}$} & \multirow{2}{*}{ Remark } \\
\hline & $\mathrm{P}_{1}$ & $\mathrm{P}_{2}$ & & $\mathrm{P}_{1}$ & $\mathrm{P}_{2}$ & $\mathrm{P}_{1}$ & $\mathrm{P}_{2}$ & & & & & & & $\begin{array}{c}\text { EXP_Reg } \\
\text { (a) }\end{array}$ & $\begin{array}{c}\text { EXP_S } \\
\text { (b) }\end{array}$ & $\begin{array}{l}\text { HEU } \\
\text { (c) }\end{array}$ & (c) - (b) & (c) - (a) & \\
\hline Base & 1 & 1 & $\mathbf{c}_{\mathbf{b}}^{\mathbf{e} *}$ & 80 & 80 & 30 & 30 & 60 & 100 & 74.22 & 1,924 & 12,365 & 10,922 & $255,604.4$ & $270,243.7$ & $311,836.8$ & 13,34 & 18,03 & Basic case \\
\hline 1 & 0.8 & 1 & $\mathbf{c}_{\mathbf{b}}^{\mathbf{e} *}$ & 80 & 80 & 30 & 30 & 60 & 100 & 74.22 & 1,924 & 12,365 & 10,923 & $253,178.4$ & $267,793.5$ & $304,288.7$ & 11,99 & 16,80 & $\mathrm{Z}_{1}^{*} \leftrightarrow, \mathrm{C}^{*} \downarrow$ \\
\hline 2 & 1.2 & 1 & $\mathbf{c}_{\mathbf{b}}^{\mathbf{e} *}$ & 80 & 80 & 30 & 30 & 60 & 100 & & 1,924 & 12,365 & 10,923 & $258,030.1$ & $272,694.0$ & $319,384.9$ & 14,62 & 19,21 & $\mathrm{Z}_{1}^{*} \leftrightarrow, \mathrm{C}^{*} \uparrow$ \\
\hline 3 & 1 & 0.8 & $\mathbf{c}_{\mathbf{b}}^{\mathbf{e} *}$ & 80 & 80 & 30 & 30 & 60 & 100 & 75.77 & 1,855 & 12,365 & 12,369 & $253,338.3$ & $265,596.4$ & $305,634.1$ & 13,10 & 17,11 & $\mathrm{U}_{\mathrm{st}}^{\mathrm{r} *} \downarrow, \mathrm{Z}_{2}^{*} \uparrow, \mathrm{C}^{*} \downarrow$ \\
\hline 4 & 1 & 1.2 & $\mathbf{c}_{\mathbf{b}}^{\mathbf{e} *}$ & 80 & 80 & 30 & 30 & 60 & 100 & 71.75 & 2,037 & 12,365 & 9,072 & $257,547.8$ & $274,891.2$ & $318,039.5$ & 13,57 & 19,02 & $\mathrm{U}_{\mathrm{st}}^{\mathrm{r} *} \uparrow, \mathrm{Z}_{2}^{*} \downarrow, \mathrm{C}^{*} \uparrow$ \\
\hline 5 & 1 & 1 & $0.8 c_{b}^{e}$ & 80 & 80 & 30 & 30 & 60 & 100 & 75.70 & 1,858 & 12,365 & 12,295 & $250,532.6$ & $262,827.0$ & $303,236.8$ & 13,33 & 17,38 & $\mathrm{U}_{\mathrm{st}}^{\mathrm{r} *} \downarrow, \mathrm{Z}_{2}^{*} \uparrow, \mathrm{C}^{*} \downarrow$ \\
\hline 6 & 1 & 1 & $1.2 c_{b}^{e}$ & 80 & 80 & 30 & 30 & 60 & 100 & & & 12,365 & 9,175 & $260,389.4$ & $277,659.6$ & $320,436.8$ & & & $\mathrm{U}_{\mathrm{st}}^{\mathrm{r} *} \uparrow, \mathrm{Z}_{2}^{*} \downarrow, \mathrm{C}^{*} \uparrow$ \\
\hline 7 & 1 & 1 & $\mathbf{c}_{\mathbf{b}}^{\mathbf{e} *}$ & 60 & 80 & 30 & 30 & 60 & 100 & 74.22 & 1,924 & 12,365 & 10,918 & $255,278.5$ & $269,912.9$ & $311,836.5$ & 13,44 & 18,14 & $\mathrm{Z}_{1}^{*} \leftrightarrow, \mathrm{C}^{*} \downarrow$ \\
\hline 8 & 1 & 1 & $\mathbf{c}_{\mathbf{b}}^{\mathbf{e} *}$ & 100 & 80 & 30 & 30 & 60 & 100 & 74.22 & 1,924 & 12,365 & 10,918 & $255,929.9$ & $270,574.4$ & $311,837.0$ & 13,23 & 17,93 & $\mathrm{Z}_{1}^{*} \leftrightarrow, \mathrm{C}^{*} \uparrow$ \\
\hline 9 & 1 & 1 & $\mathbf{c}_{\mathbf{b}}^{\mathbf{e} *}$ & 80 & 60 & 30 & 30 & 60 & 100 & 73.34 & 2,010 & 12,365 & 9,927 & $255,397.1$ & $270,063.8$ & $311,664.5$ & 13,35 & 18,05 & $\mathrm{U}_{\mathrm{st}}^{\mathrm{r} *} \uparrow, \mathrm{Z}_{2}^{*} \downarrow, \mathrm{C}^{*} \downarrow$ \\
\hline 10 & 1 & 1 & $\mathbf{c}_{\mathbf{b}}^{\mathbf{e} *}$ & 80 & 100 & 30 & 30 & 60 & 100 & 74.92 & 1,862 & 12,365 & 11,621 & $255,807.5$ & $270,423.4$ & $312,009.0$ & 13,33 & 18,01 & $\mathrm{U}_{\mathrm{st}}^{\mathrm{r} *} \downarrow, \mathrm{Z}_{2}^{*} \uparrow, \mathrm{C}^{*} \uparrow$ \\
\hline 11 & 1 & 1 & $\mathbf{c}_{\mathbf{b}}^{\mathbf{e} *}$ & 80 & 80 & 25 & 30 & 60 & 100 & 74.22 & 1,924 & 12,365 & 10,918 & $242,073.7$ & $256,709.6$ & $298,305.4$ & 13,94 & 18,85 & $\mathrm{Z}_{1}^{*} \leftrightarrow, \mathrm{C}^{*} \downarrow$ \\
\hline 12 & 1 & 1 & $\mathbf{c}_{\mathbf{b}}^{\mathbf{e} *}$ & 80 & 80 & 35 & 30 & 60 & 100 & 74.22 & 1,924 & 12,365 & 10,918 & $269,133.6$ & $283,777.6$ & $325,368.2$ & 12,78 & 17,28 & $\mathrm{Z}_{1}^{*} \leftrightarrow, \mathrm{C}^{*} \uparrow$ \\
\hline 13 & 1 & 1 & $\mathbf{c}_{\mathbf{b}}^{\mathbf{e} *}$ & 80 & 80 & 30 & 25 & 60 & 100 & 75.82 & 1,853 & 12,365 & 12,421 & $252,310.9$ & $260,826.8$ & $302,418.7$ & 13,75 & 16,57 & $\mathrm{U}_{\mathrm{st}}^{\mathrm{r} *} \downarrow, \mathrm{Z}_{2}^{*} \uparrow, \mathrm{C}^{*} \downarrow$ \\
\hline 14 & 1 & 1 & $\mathbf{c}_{\mathbf{b}}^{\mathbf{e} *}$ & 80 & 80 & 30 & 35 & 60 & 100 & 69.10 & 2,159 & 12,365 & 7,399 & $258,166.8$ & $279,659.9$ & $321,254.9$ & 12,95 & 19,64 & $\mathrm{U}_{\mathrm{st}}^{\mathrm{r} *} \uparrow, \mathrm{Z}_{2}^{*} \downarrow, \mathrm{C}^{*} \uparrow$ \\
\hline 15 & 1 & 1 & $\mathbf{c}_{\mathbf{b}}^{\mathbf{e} *}$ & 80 & 80 & 30 & 30 & 55 & 100 & 69.02 & 2,161 & 12,365 & 7,370 & $245,461.0$ & $267,493.9$ & $309,086.8$ & 13,46 & 20,59 & $\mathrm{U}_{\mathrm{st}}^{\mathrm{r} *} \uparrow, \mathrm{Z}_{2}^{*} \downarrow, \mathrm{C}^{*} \downarrow$ \\
\hline 16 & 1 & 1 & $\mathbf{c}_{\mathbf{b}}^{\mathbf{e} *}$ & 80 & 80 & 30 & 30 & 65 & 100 & 75.88 & 1,843 & 12,365 & 12,435 & $265,009.5$ & $272,993.7$ & $314,586.8$ & 13,22 & 15,76 & $\mathrm{U}_{\mathrm{st}}^{\mathrm{r} *} \downarrow, \mathrm{Z}_{2}^{*} \uparrow, \mathrm{C}^{*} \uparrow$ \\
\hline
\end{tabular}

Table 7. Sensitivity analysis of model EXP_Reg for a 99.5\% service level and improvement cost comparison

Where EXP_Reg: joint production / regular subcontracting control policy, EXP_S: Experimental solution approach based on Dror's control policy, HEU: Heuristic solution approach proposed by Dror et al. [1].

$* \mathbf{c}_{\mathbf{b}}^{\mathbf{e}}$ : the storage space cost for the base case. It is represented by a step cost depending on intervals of $Z_{i}$ values. For example, if $Z_{i} \in[0,999]$ then $c_{b}^{e}=1400$, else if $Z_{\mathrm{i}} \in[1000,1999]$ then $c_{b}^{e}=1750$, etc. 
The results of the sensitivity analysis show that the approach adopted in this work is robust, and can significantly reduce the total cost of the studied production system. In fact, in comparison with the solution of Dror et al. [1], the joint production / regular subcontracting control policy (EXP_Reg) developed in this article is more advantageous in terms of the total incurred cost. Indeed, the gain achieved by combining the experimental solution approach with EXP_Reg varies between $15.76 \%$ and $20.59 \%$ (Table 7 - Improvement cost).

\section{Conclusions}

In this article, we studied a complex production and subcontracting planning optimization problem of a manufacturing system, which is a common problem in the pharmaceutical industry. The system considered consists of multiple facilities of different capacities, prone to random breakdowns and repairs. They produce two separate part types: a brand name product protected by a patent and another generic product that may be obtained from external sources to completely satisfy customer demand. A control policy is proposed which simultaneously combines the production and the subcontracting planning of the production system. Because of the complexity of the system considered and the limitations of analytical solution approaches, we adopted an experimental approach by integrating the simulation with statistic optimization techniques. This solution approach consists in experimentally determining the optimal value of the control parameters that minimize the total cost incurred by taking into account the customer satisfaction constraint. Thus simultaneously considering the cost and the customer satisfaction better approximates the concerns of the company's decision makers. The combination of the experimental approach with the joint production / regular subcontracting control policy achieved improvements in terms of cost, up to $20 \%$ compared to an existing model in the literature [1]. We have also demonstrated that for economic reasons, the system chooses to increase the value of the regular subcontracting rate instead of internal production in order to achieve a greater service level. Other control policies using urgent subcontracting parameters as decision variables are also integrated into the comparison. According to our policy, the pharmaceutical company has no interest in considering urgent subcontracting for the real case studied by Dror et al. [1]. Consequently, the joint production/regular subcontracting control policy proposed in this article outperforms Dror's proposal not only in term of total incurred cost, but also it is more easy to 
manage and very useful to ensure an efficient control and an effective traceability of the subcontracted products. Sensitivity analyses were performed and some interesting behaviors were observed, confirming the robustness of the solution approach used and the effectiveness of the proposed control policy.

Further extensions of the proposed control policy could be considered. In fact, quality-review system can be adopted for the case where the supplier manufactures items with defective ratio (see [36]). In addition, it should be noted that in this work, we ignored the setup time and setup cost parameters because both products have the same basic chemical characteristics since the brand name and the generic medications are composed of the same main chemical substances. However, in some situations, finished products are more distinct, and switching from one product type to another requires significant setup time and cost (i.e., non-flexible machines). In this case, the control policy could be based on a single hedging point (SHP) structure (one hedging point per product) as in [20] or on a multiple hedging point (MHP) structure as in [21] (two hedging points per product) and [37] (three hedging points per product). The latter [37] shows that the MHP policy is more effective in terms of the costs than the SHP policy for the one-machine two-products case. However, using the cost and the customer satisfaction level as two key performance indicators, the SHP may be more effective. Theses control policy structures will be considered in our future research work to check their effectiveness for the manufacturing system presented in this paper (multiple-machine, two-products, subcontracting, etc.). Preventive maintenance strategies could also be considered as in [13] and [38] in order to propose an effective joint subcontracting/production/maintenance control policy. The goal is to reduce the number of major failures and the risk of shortage.

\section{References}

[1] Dror, M., Smith, K. R., \& Yano, C. A. (2009). Deux Chemicals Inc. Goes Just-in-Time. Interfaces, 39 (6), pp. 503-515.

[2] Whittle, P. (1996). Optimal Control: Basics and Beyond. New York: John Wiley \& Sons, $474 \mathrm{p}$.

[3] Meijboom, B., \& Obel, B. (2007). Tactical coordination in a multi-location and multi-stage operations structure:Amodel and a pharmaceutical company case. OMEGA: The International Journal of Management Science, 35, pp. 258-273. 
[4] eHow. "Types of Pharmaceutical Companies." 1999. www.ehow.com/list_6873820_typespharmaceutical-companies.html (accessed 02 june 2012).

[5] Kaplan, W.A., \& Laing, R. (2005). Local production of pharmaceuticals: Industrial policy and access to medicines. An overview of key concepts, issues and opportunities for future research. HNP Discussion Papers. World Bank, Washington DC.

[6] Booth, R. (1996). The role of supply-chain re-engineering in the pharmaceutical industry. Logistics information management, 9 (3), pp. 4-10.

[7] Olsder, G. J., \& Suri, R. (1980). Time-optimal control of parts-routing in a manufacturing system with failure-prone machines. Proceedings of the 19th conference on decision and control. Albuquerque, NM.

[8] Richel, R. (1975). Dynamic programming and minimum principles for systems with jump Markov disturbances. SIAM Journal on Control, 13, pp. 338-371.

[9] Kimemia, J. \& Gershwin, S.B. (1983). An Algorithm for the Computer Control of a Flexible Manufacturing System. IIE Transactions, 15 (4), pp. 353-362.

[10] Akella, R., \& Kumar, P.R. (1986). Optimal Control of Production Rate in a Failure Prone Manufacturing System. IEEE Transactions on Automatic Control, 31 (2), pp. 116-126.

[11] Sharifnia, A. (1988). Production Control of a Manufacturing System with Multiple Machine States. IEEE Transactions on Automatic Control, AC-33 (7), pp. 600-626.

[12] Feng, Y. \& Yan, H. (2000). Optimal Production Control in a Discrete Manufacturing System with Unreliable Machines and Random Demands. IEEE Transactions on Automatic Control, 45 (11), pp. 2280-2296.

[13] Berthaut, F., Gharbi, A., \& Dhouib, K. (2011). Joint modified block replacement and production/inventory control policy for a failure-prone manufacturing cell. OMEGA: The International Journal of Management Science, 39 (6), pp. 642-654.

[14] Dhouib, K., Gharbi, A., \& Ben Aziza, M.N. (2012). Joint optimal production control/preventive maintenance policy for imperfect process manufacturing cell. International Journal of Production Economics, 137 (1), pp. 126-136.

[15] Chakraborty, T., Giri, B.C. \& Chaudhuri, K.S. (2009). Production lot sizing with process deterioration and machine breakdown under inspection schedule. OMEGA: The International Journal of Management Science, 37, pp. 257-271.

[16] Jeang, A. (2012). Simultaneous determination of production lot size and process parameters under process deterioration and process breakdown. OMEGA: The International Journal of Management Science, 40, pp. 774-781.

[17] Caramanis, M., \& Sharifnia, A. (1991). Near Optimal Manufacturing Flow Controller Design. The International Journal of Flexible Manufacturing Systems, 3, pp. 321-336.

[18] Sethi, S. P., \& Zhang, Q. (1999). Average-Cost Optimal Policies for an Unreliable Flexible Multiproduct Machine. The International Journal of Flexible Manufacturing Systems, 11, pp. 147-157.

[19] Gharbi, A., \& Kenné, J. P. (2003). Optimal production control problem in stochastic multiple-product multiple-machine manufacturing systems. IIE Transactions, 31, pp. 941-952. 
[20] Bai, S.X., \& Elhafsi, M. (1997). Scheduling of an unreliable manufacturing system with non-resumable set-ups. Computers Ind. Eng., 32, pp. 909-925.

[21] Gharbi, A., Kenné, J. P., \& Hajji, A. (2006). Operational level-based policies in production rate control of unreliable manufacturing systems with set-ups. International Journal of Production Research, 44 (3), pp. 545-567.

[22] Dellagi, S., Rezg, N., \& Xie, X. (2007). Preventive maintenance of manufacturing systems under environmental constraints. International Journal of Production Research, 45 (5), pp. 12331254.

[23] Ayed, S., Dellagi, S., \& Rezg, N. (2012). Joint optimisation of maintenance and production policies considering random demand and variable production rate. International Journal of Production Research, 50 (23), pp. 6870-6885.

[24] Gharbi, A., Hajji, A., \& Dhouib, K. (2011). Production rate control of an unreliable manufacturing cell with adjustable capacity. International Journal of Production Research, 49 (21), pp. 6539-6557.

[25] Ponsignon, T., Mönch L. (2014). Simulation-based performance assessment of master planning approaches in semiconductor manufacturing. OMEGA: The International Journal of Management Science, 46, pp. 21-35.

[26] Dye, C.Y. (2013). The effect of preservation technology investment on a non-instantaneous deteriorating inventory model. OMEGA: The International Journal of Management Science, 41, pp. 872-880.

[27] Wee, H. M. Widyadana, G. A. (2013). A production model for deteriorating items with stochastic preventive maintenance time and rework process with FIFO rule. OMEGA: The International Journal of Management Science, 41, pp. 941-954.

[28] Lavoie, P., Gharbi, A. \& Kenné, J. P. (2010). A comparative study of pull control mechanisms for unreliable homogenous transfer lines. International Journal of Production Economics, 124, pp. 241-251.

[29] De Garmo, E.P., Sullivan, W.G. \& Bontadelli, J.A. (1989). Engineering Economy. $8^{\text {th }}$ Ed. New York: MacMillan.

[30] Kenné, J. P. \& Gharbi, A. (2000). Production planning problem in manufacturing systems with general failure and repair time distributions. Production Planning \& Control, 11(6), pp. 581-588.

[31] Wang, Z., Chan, F. T. S. (2013). Independence of the hedging points in PHP control policy. Journal of the Operational Research Society. doi:10.1057/jors.2013.10.

[32] Mourani, I., Hennequin, S., \& Xie, X. (2008). Simulation-based optimization of a singlestage failure-prone manufacturing system with transportation delay. International Journal of Production Economics, 112 (1), pp. 26-36.

[33] Bouslah, B., Gharbi, A., Pellerin, R. (2013). Joint optimal lot sizing and production control policy in an unreliable and imperfect manufacturing system. International Journal of Production Economics, 144 (1), pp. 143-156. 
[34] Montgomery, D.C. (2008). Design and Analysis of Experiments, 7th ed., New York: John Wiley \& Sons.

[35] Banks, J., Carson, J.S., Nelson, B.L., \& Nicol, D.M. (2005). Discrete-Event System Simulation. Fourth Edition, Prentice-Hall, Upper Saddle River, NJ.

[36] Singer, M., Donoso, P., \& Traverso, P. (2003). Quality strategies in supply chain alliances of disposable items. OMEGA: The International Journal of Management Science, 31 (6), pp. 499-509.

[37] Assid, M., Gharbi, A., \& Hajji, A. (2014). Joint production and setup control policies: an extensive study addressing implementation issues via quantitative and qualitative criteria. The International Journal of Advanced Manufacturing Technology. 72(5-8), pp. 809-826.

[38] Wee, H.M., Widyadana, G.A. (2013). A production model for deteriorating items with stochastic preventive maintenance time and rework process with FIFO rule. OMEGA: The International Journal of Management Science, 41, pp. 941-954. 